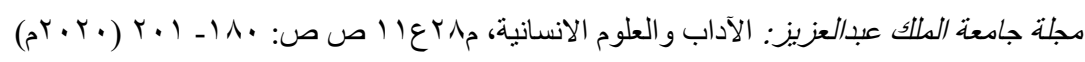

$$
\begin{aligned}
& \text { DOI:10.4197/Art.28-11.8 }
\end{aligned}
$$

\title{
موقف أئمة الزيدية من المخالفين \\ (عبدالله بن حمزة نموذجاً)
}

\author{
د. عبدالرحمن بن علي بن أحمد الزهراني

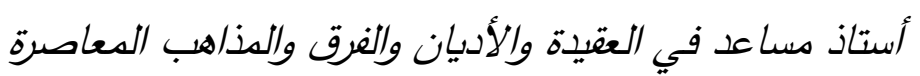

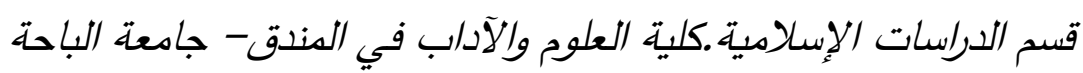

مستخلص. يدرس هذا البحث موقف فرقة الزيدية ممن خالفهم من الفرق ، وذلك من خلال دراسة أحد أهم أئمتهم وأبرزهم وهو عبدالله بن حمزة.

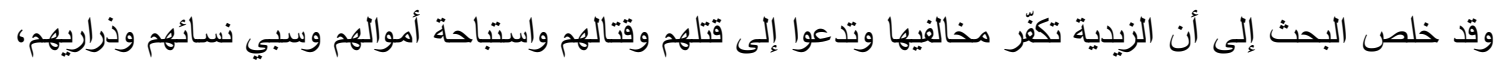

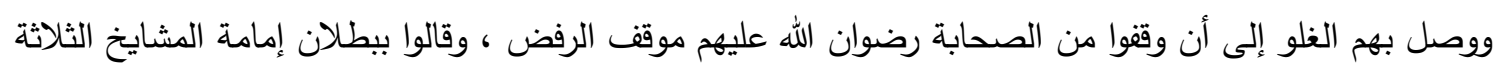

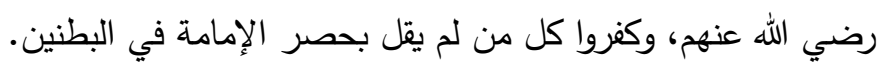

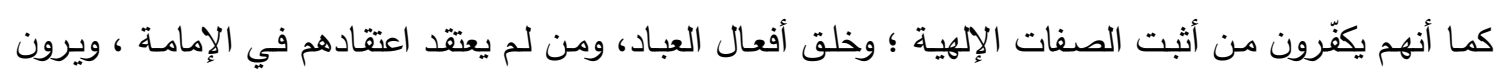
إعمال السيف فيهم.

وقد أثبت البحث غلو الزيدية في موقفهم من المخالف، وتنزيلهم الآيات التي نزلت في الكفر الأكبر على المسلمين

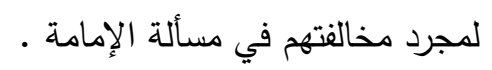
الكلمات المفتاحية : موقف، الزيدية، المخالفين، عبدالله بن حمزة.

إلا الله وحده لا شـريك لـه، وأثـهـ أن محمـداً عبده ورسوله

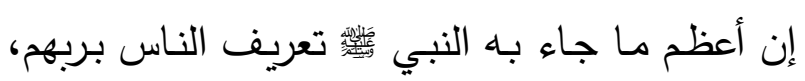

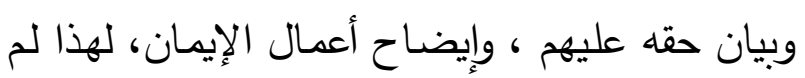

\section{المقدمة}

إن الحمد لله نحمده ونستعينه ونستغغره ، ونعوذ بالله من شرور أنفسنا ومن سيئات أعمالنا، من يهده الله فلا مضل له ومن يضلل فلا هادي له، وأشهر ألا إله 
و كيف أنهم يضيّقون دائرة الإسـلام عن المسلمين

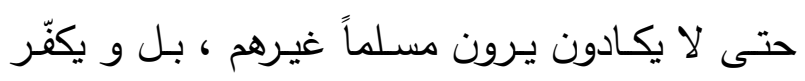

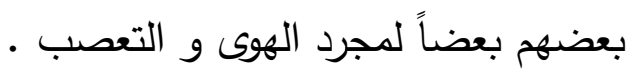
و لكثف هذا الجانب فقد اخترت شخصية من أئمتهم لها مكانتها في المذهب و هو الإمام الزيدي عبدالله

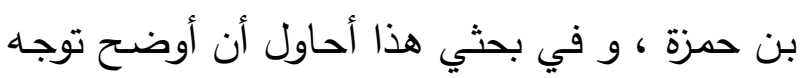

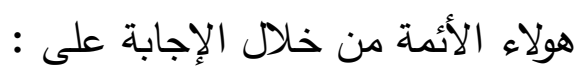

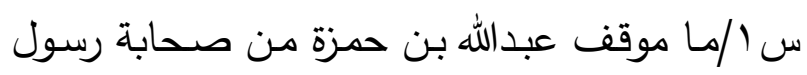

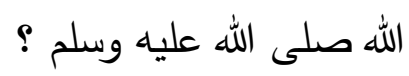

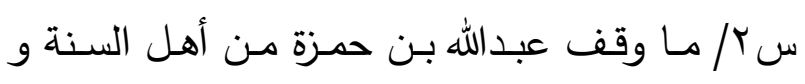
الجماعة ؟ س س/ ما موقف عبدالله بن حمزة من فرقة المُطرفية الزيدية ؟

س \& / ما موقف ابن حمزة من الخوارج و الباطنية ؟

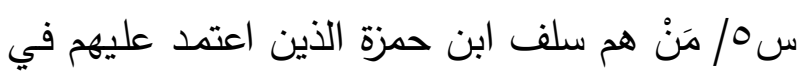
مواقفه مع من خالفه ؟

\section{أهمية وأهداف الموضوع}

1- التعـرف على موقـف عبــالله بـن حمـزة مـن

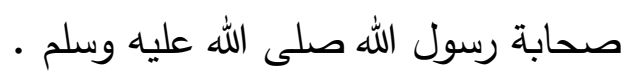

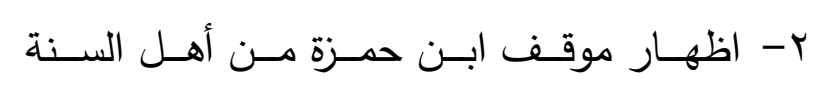
والجماعة. ب- بيان موقف ابن حمزة من المُطرفيـة ، و سبب اتخاذه ذلك الموقف مع أنهم زيدية. ع- مقارنـة موقف ابن حمزة من الخوارج والباطنيـة

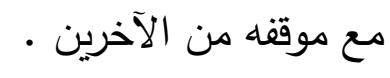

يقـع خـلاف بين صـابته و لا تابعيهم في مسـألة الإيمان فهي من الوضوح بمكان ، حيث ثبت فيها

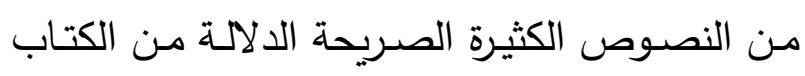
السنة والآثار ما يبيّن أن الإيمان قول وعمل ، وأن أنسي

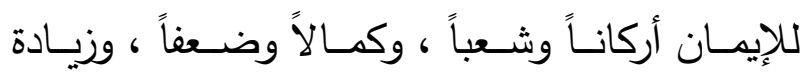

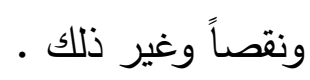
و قد سـار أهل السنة والجماعـة في سـائر العصور على منهاج السلف الصسالح في كل ذلك ، و و افترق لـن

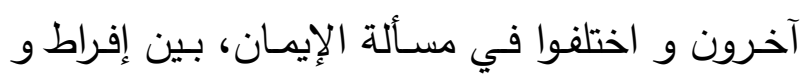

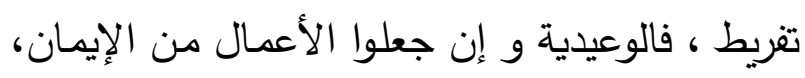

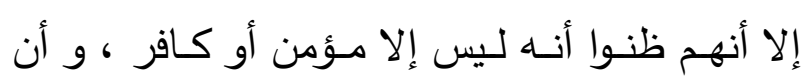

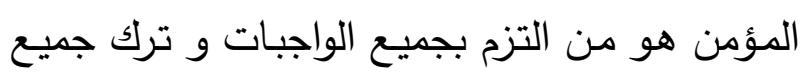

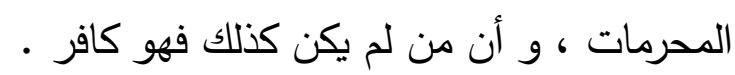

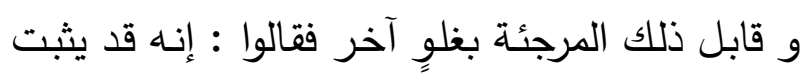

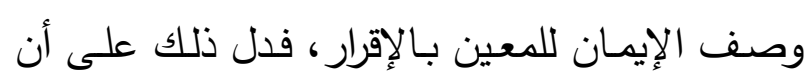

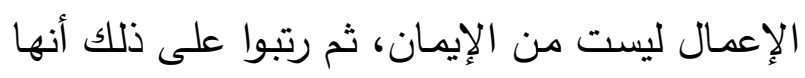

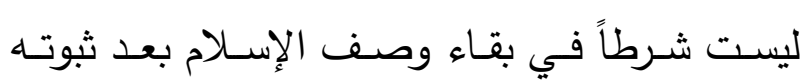

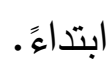

و مع هذا فإن من الفرق من يتهم من سار على الفى

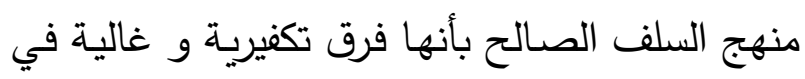

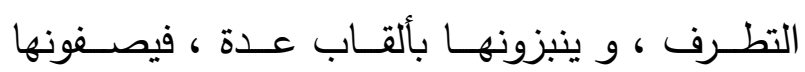
بالوهابية و الأصولية وغيرها.

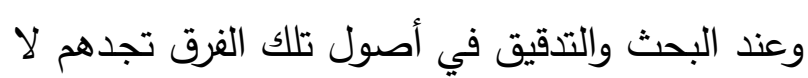

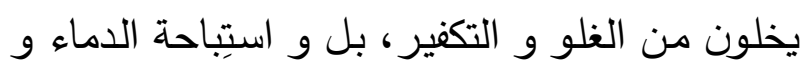

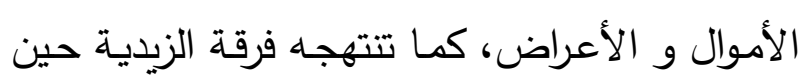
تتمكن من الحكم كما سيظهر في بحثنا هذا. 
أولاً : اسمه وصفته .

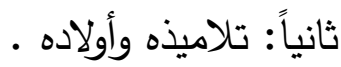

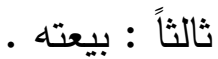

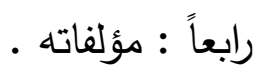

خامساً : عقيدته . رولهاته : رابعا

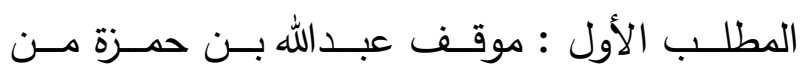

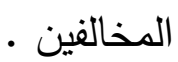

المطلب الثاني : موقفه من الصحابة .

المطلب الثالث : موقفه من أهل السنة والجماعة .

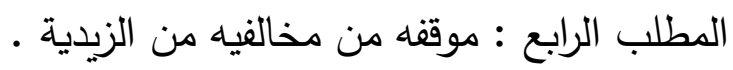
المطلب الخامس : موقفه من الخوارج. المطلب السادس : موقفه من الباطنية .

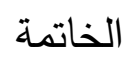

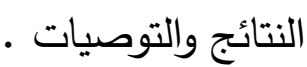

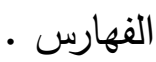

التمهيد

حياته و عقيدته

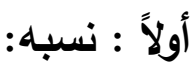

هو أبو محمد عبد الله بن حمزة بن سليمان بن حمزة بن علي بن حمزة بن الحسن بن عبد الرحمن بن يحيى بن عبد الله بن

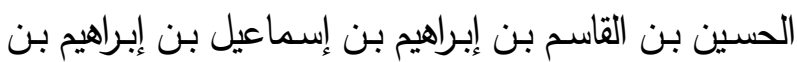

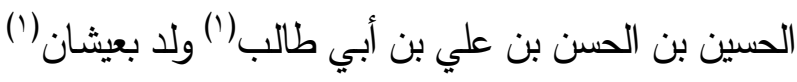

\footnotetext{
(1) (الحدائق الوردية في مناقب الأئمة الزيدية ، حميد أحمد محمد المحلي

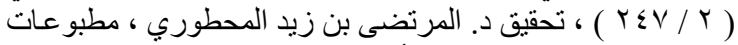

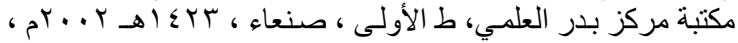

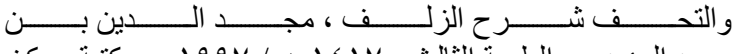

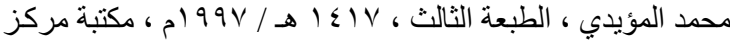

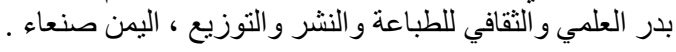

ه- إيضاح سلف ابن حمزة في مواقفه التي اتخذها حيال المخالفين له . - اله

\section{الاراسات السابقة - ابة}

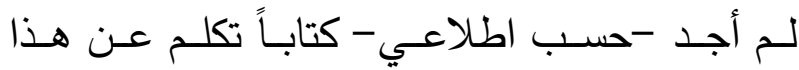
الموضوع سوى بعض الكتابات الصحفية فقط .

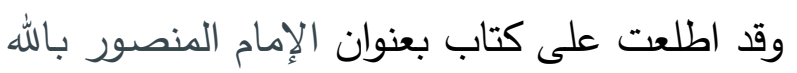
عبد الله بن حمزة و دوره في إحياء الدولة الزيدية في

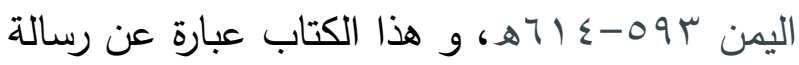

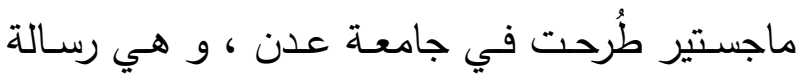

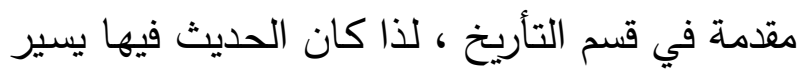

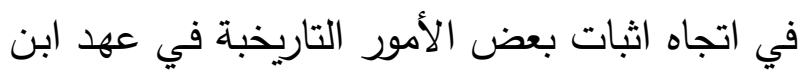
حمـزة ، وعلاقتـهـ السياسـية مـع غيـره ، و المظــاهر

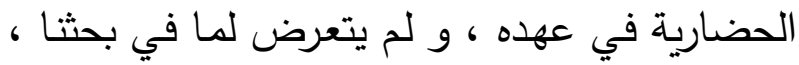

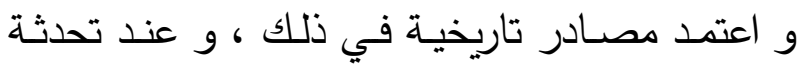

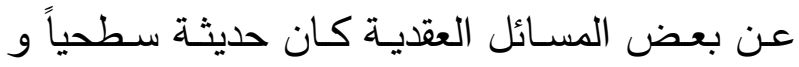
بسيطاً ، و لم ينقل من كتب ابن حمزة إلا في القليل

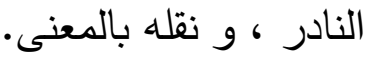

\section{حدود البحث}

حدوده الزمانية : حياة عبد الله بن حمزة من مبايبعته

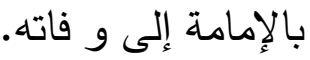
حدوده الموضوعية : جانب من مواقف عبدالله بن حمزة من أهل السنة و المطرفية والخوارج و الباطنية من خلال كتبة التي وقفت عليها. خطة البحث

$$
\text { التمهيد: حياته وعقدت البحث إلى: }
$$


، و اجتمع علماء الزيدية هناك و حاوروه و ناظروه

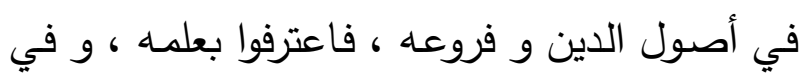
يوم الجمعة الثالث عشر من شهر ربيع الأول سنة

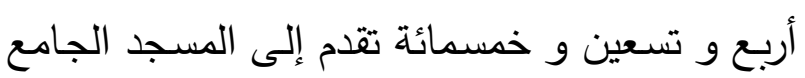

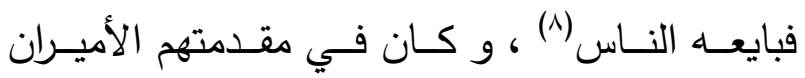
الداعيان اللذان عرض عليهما هو الإمامة و لكنهما

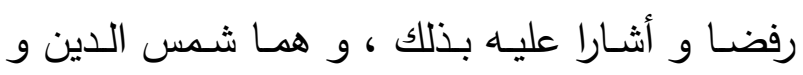

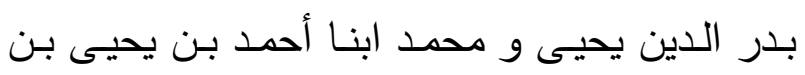

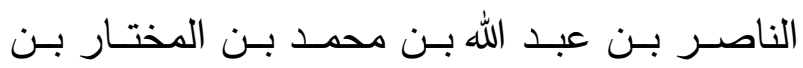

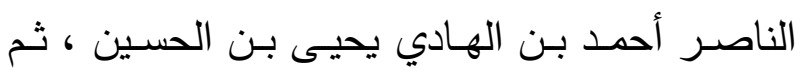

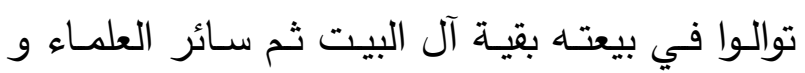
شيعتهم (9) و بعد ذلك استقر بناصية صعدة ، وفرّق داعاته في

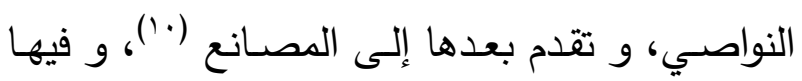
بايعه أكابر فرقة المطرفية(1)

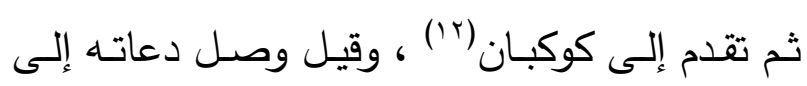

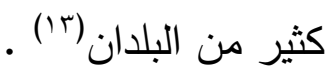
رابعاً : مؤلفاته : من البلان

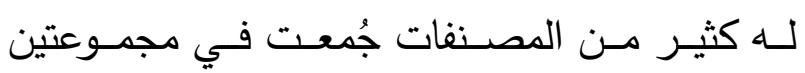

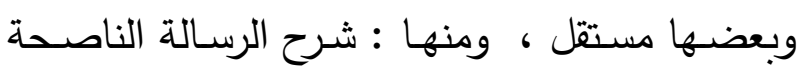

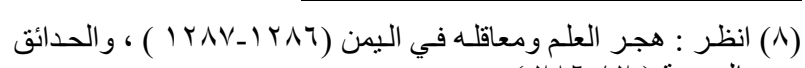

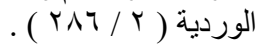

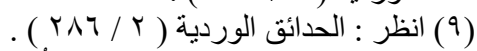

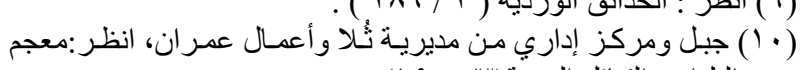

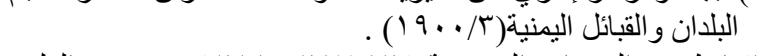

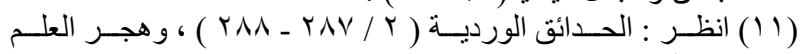

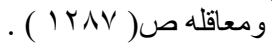

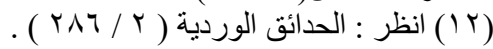

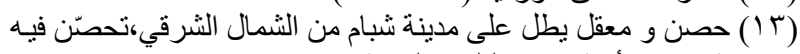

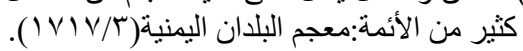

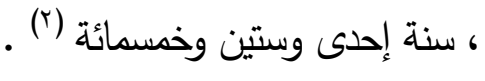
ثانياً : تلاميذه و أولاده :

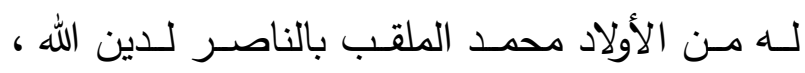

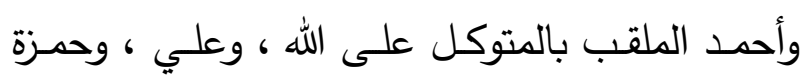

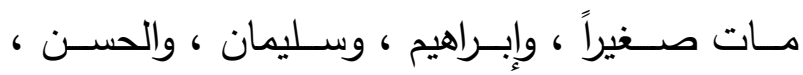

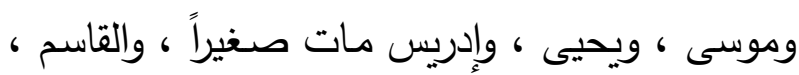

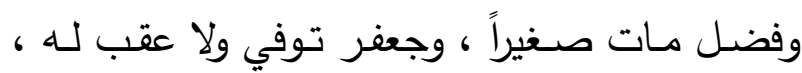

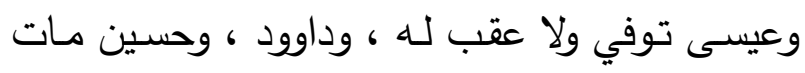
صغيراً . صعان.

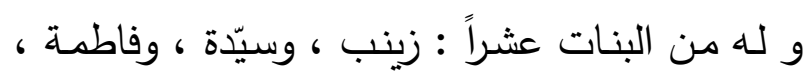

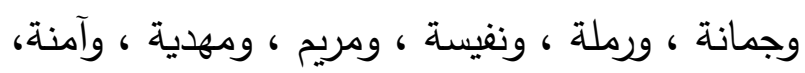

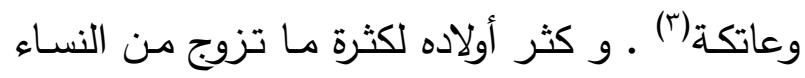

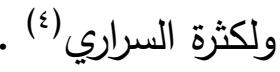

ثالثاً : بيعته : برة الثرائ

كانت دعوته العامة للإمامة في شهر ذي القعدة سنة

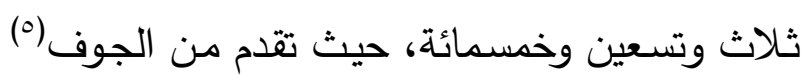

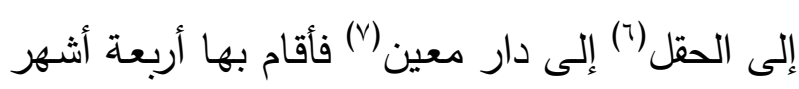

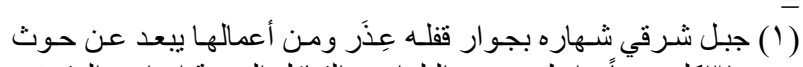

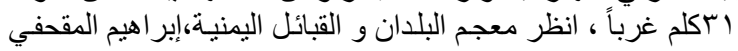

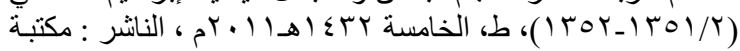

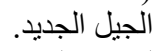

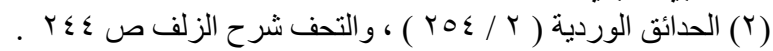

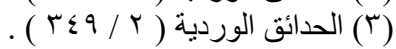

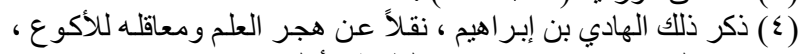

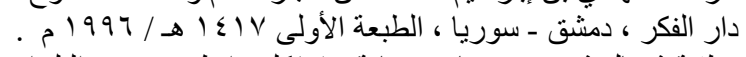

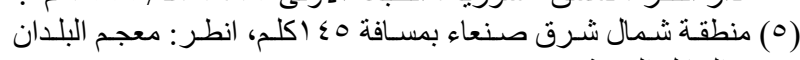

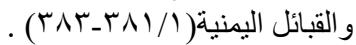

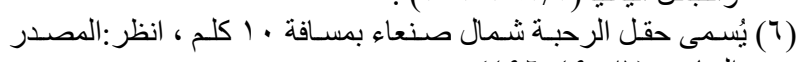

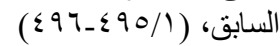

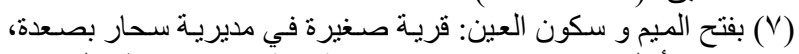

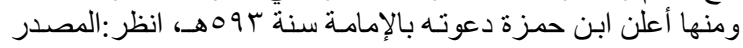

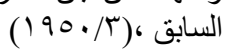


رسـالته الموسـومة بزبـــــالأدلــة فـي معرفـة الله ، و

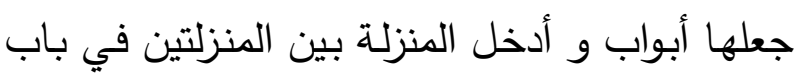

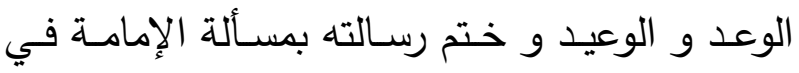
نهاية الرسالة . و لذلك سأكتفي بذكر نماذج من رسالته زبد الأدلة لتوضيح رسالته لاسيما و قد كتبها بطريقة السؤال و

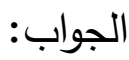
فهو يقول بأن النظر أول الواجبات على المره، و يسير على طريقة المتكلمين في دليل الحدوث . فقال تحت باب القول في التوحيد؛ في مسألة دئة دئل إيجاب النظر: - - إن ״ إن قيل : ما أول ما أوجب الله عليك ؟

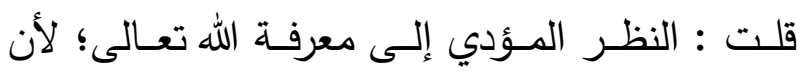

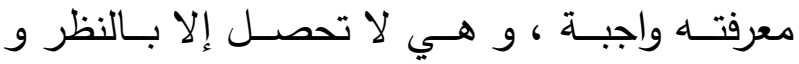

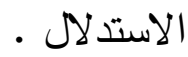
فـإن قيل : مـا الـدليل على أن للعـالم صـانعاً حتى يوجب معرفته أو لا يوجبها ؟

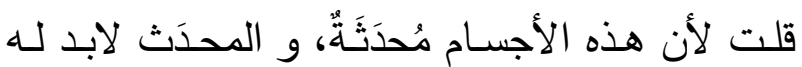
من محدِثه (') ثم يشرح دليل الحدوث مستخدماً له في نفي الصفات الإلهية (r)

ويقول في نفي الرؤية:

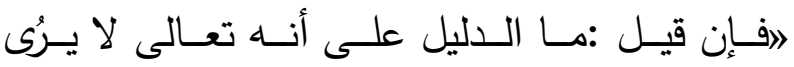

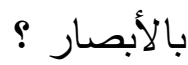

بالأدلة الواضحة ، وهو مشتمل على جزأين ، الأول

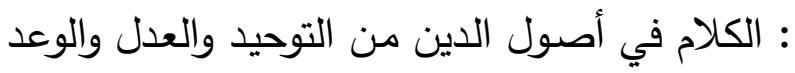
والوعيد والنبوات ، والثاني : الكلام في فضائل العترة

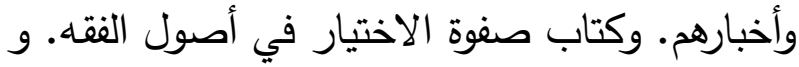

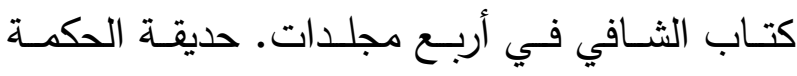
النبويـة في تفسير الأربعـين السـليقية. و الرسـالة الهادية بالأدلة البادية ، في السبي وما يتعلق به. و و

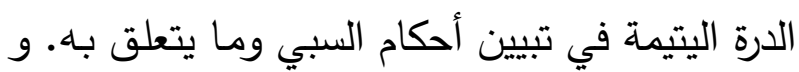

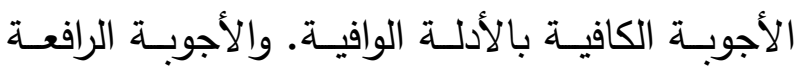

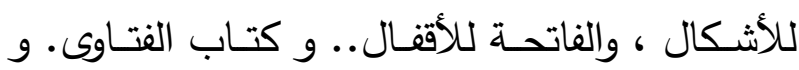
الرسالة الفارقة بين الزيدية والمارقة، في الكلام على المطرفية. و هداية المسترشدين. و العقد الثمين في لري لرئه

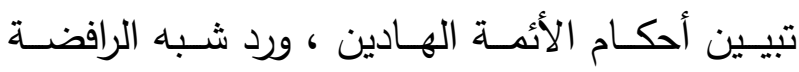
الغالين. و الرسالة المرتضـاه في العهد إلى القضاة.

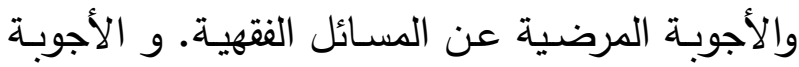
الثافية عن المسائل المتنافية ـ و البيان والثبات إلى لى الثيل كافة البنين والبنات ، وغيرها.

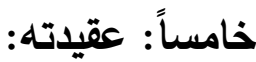
لقد سار عبد الله بن حمزة سيرة من قبله في اعتقاده

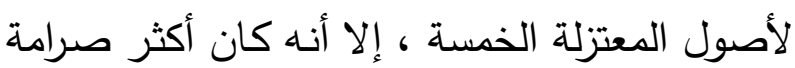

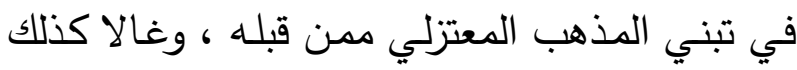

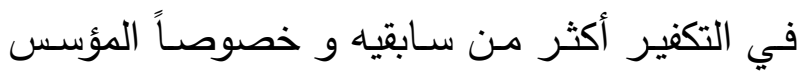

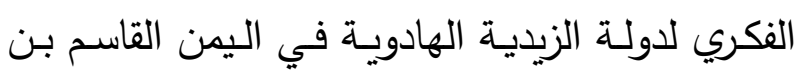

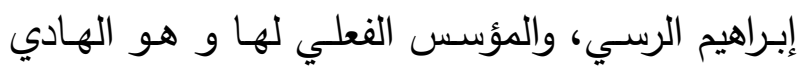
يحيى بن الحسين •

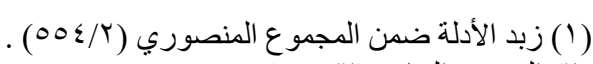

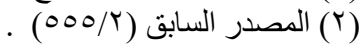

فعبد الله بن حمزة أتى بأصول المعتزلة الخمسة في 


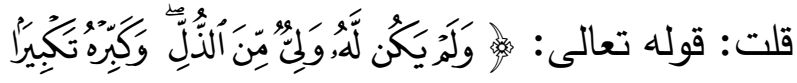

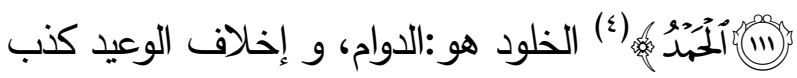

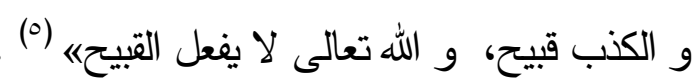
• و يقول بالمنزلة بين المنزلتين ، كما جاء تحت لإيت

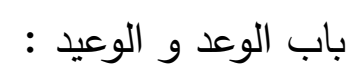

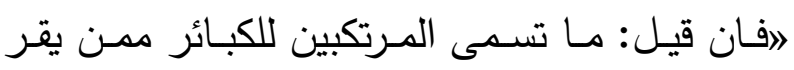

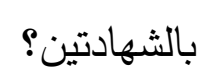

قلت: أسميهم فساقاً و لا أسميهم كفاراً ؛ لأن الكفر

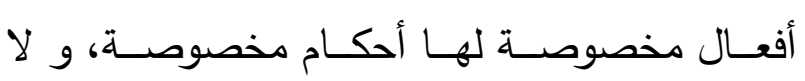

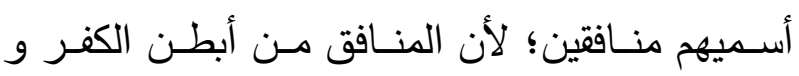
أظهر الإسـلام، و لا أسميهم مؤمنين؛ لأن الإيمان اسم شرف، و الفاسق يستحق الإهانة فلم يبق سالماً

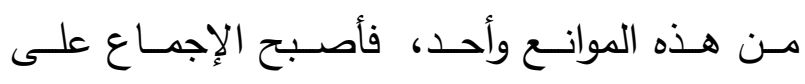
تسميتهم فساقاً (1).

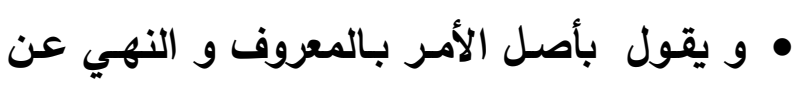

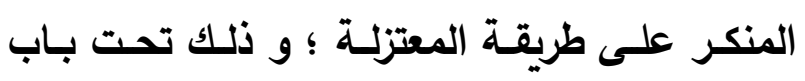

\section{الوعد و الوعيد :}

"افنان قيل :لمـا قلت أن الأمـر بالمعروف و النهي

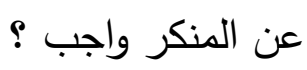

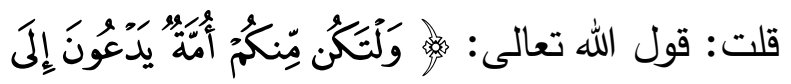

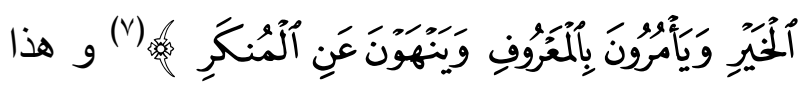
أمر و الأمر يقتضي الوجوب «(^).

(؛)سورة الجن، آية (بT).

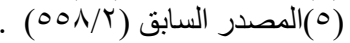

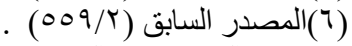

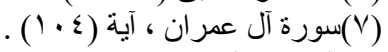

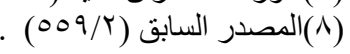

قلت: لأنها لو صحت رؤيته في حال من الأحوال لرأيناه الآن؛ لأن الحواس سليمة والموانع مرتفعـة و

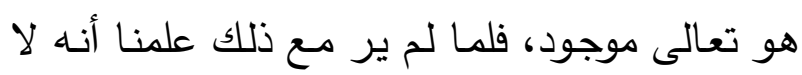
يرى بالأبصار في الانيا و الآخرة « (1). • كما يقول بخلق القرآن :

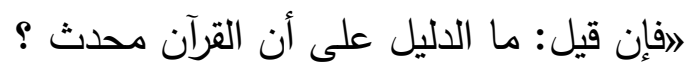
قلت: لأنه مرتب منظوم يوجد بعضه في إثر بعض الثران

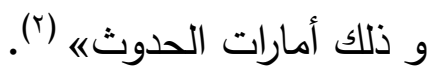

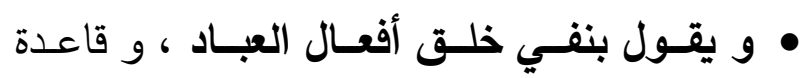
التحسين و التتبيح الكلاميـة، فقد قرر تحت بـت بـاب القول في العدل :

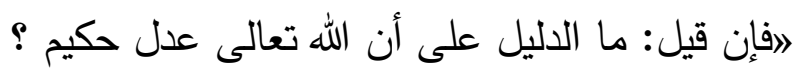
قلت: لأنه لا يحمل علي الجور و العبث إلائ العالئ الحاجة

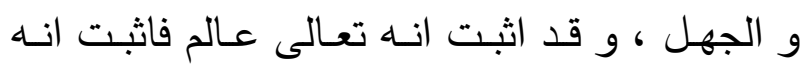

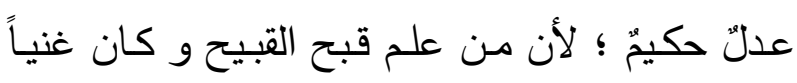
عنه لم يفعله أصلاً شاهداً و غائباً. فإن قيل: أفعال العباد منهم أو من الله تعالى ؟

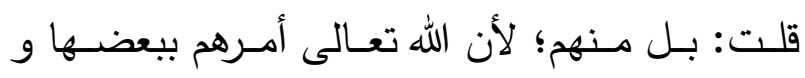

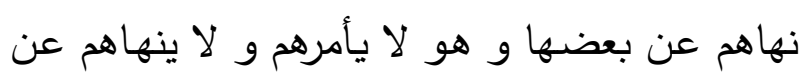

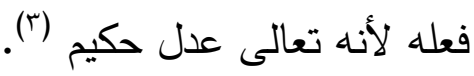
• و يقول بتخليد أصحاب المعاصي في النار ، فقد الند قررذلك تحت باب الوعد والوعيد قال:

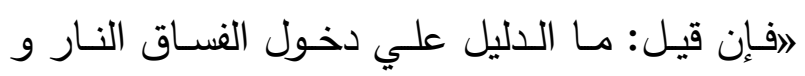
خلودهم فيها ؟ 
ويتهـددون الكفــار بـالقول ، ويفعــون فـي بعـض

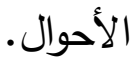

وأما دار الفسق : فهي الدار التي يظهر فيها الفسق بغير متاقاة ولاحشمة من أهل الإسلام ، لأحد الثلاثة

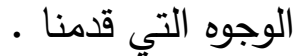
وأما دار الإسلام : فهي ما خرج من حدّ دار الكفر ،

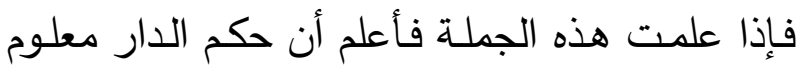
موجـود في كتب الأئعـة عليهم السـلام مـن حرمـة المناكحة ، والموارثة ، والقبر في مقابر المسلمين، إلى غير ذلك مما هو معلوم . وحكم دار الفسق عند من يوجب الهجرة منها ، وهو القاسم بن إبراهيم عليه السلام ومن تابعه من أولاده ، وقال بقوله من العلماء رضي الله عنهم أنه لا يصلّى على من مات فيها من المسلمين متمكناً من الهجرة ولم يهاجر ، ولا يقبرون في مقابر المسلمين ولا في مقابر الكفار ، وتحل مناكتهم وموارثتهح ، وذبائحهم عند بعض القاسمية ، ومنهم من منع من ذبائحهم

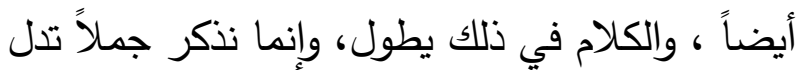

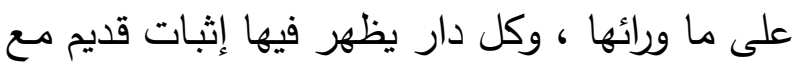
الله تعالى ، كمن يقول: بقدم القرآن، أو يثبت للباري

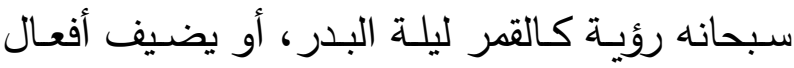
عباد الله تعالى من المخازي والقبائح إلى الله تعالى،

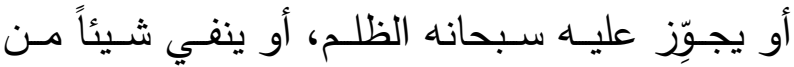

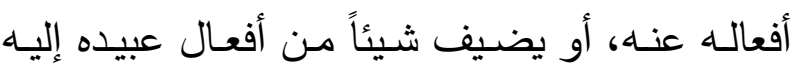
فإنـه يكون كافراً، وداره بمـا قدّمنا مـن الأخبـار دار
و معتقده في هذا الأصل يوضحه موقفه من المخالف كما سنرى في بحثنا هذا.

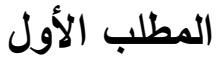

\section{موقف عبدالله بن حمزة من المخالفين}

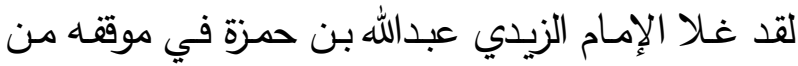

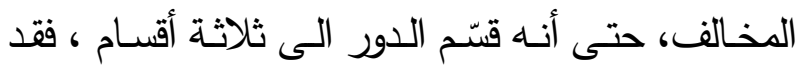
جعل للفقق داراً تخصه ؛ وجعلها تأخذ حكم دار الكفر من حيث وجوب الهجرة منها؛ وحرمة الصلاة على من مات فيها من المسلمين و لم يهاجر ؛ وكنّر من يثبت صفات الباري سبحانه؛ أو خلق أفعال العباد ، وجعل ذلك إجماعاً عند أئمة الزيدية . فقال: " فإذا قد تقررت هذه الجملة فلنذكر دار الحرب ، ودار الإسلام ، ودار الفسق ، لأن الدور عندنا ثلاث ، بكل واحدة منهما حدُ وحكم . فأمسا دار الحرب : فهي كل دار تظهر فيها خصلة أو خصلتان من خصال الكفر ، ولا يحتاج مظهرها إلى ذمـة ولا جوار ، ولا يكفي في خروجها من دار

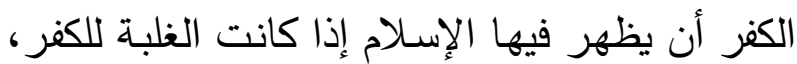

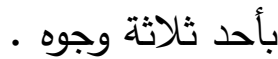
- إما أن يكون السلطان ممن يرى بتلك الأقوال أو

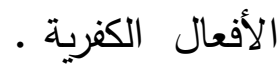
- وإما أن يكون الكفر أظهر. - وإما أن تكون الغلبة لأهله. ودليل ذلك أن مكة حرسها الله كانت قبل الهجرة دار كفر ، وفيها رسول الله يَّك والمسلمون يظهرون دينهم ولا يكـالمون فيـه أحداً ويغـالبون في بعض وله الأحـوال 


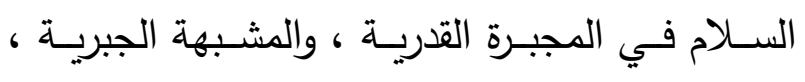
ويغزوهم ليلاً ونهاراً ، ويختطفون ذراريهم سراً وجهاراً

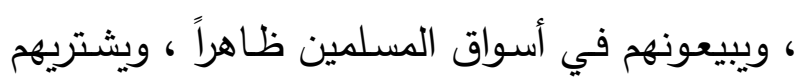

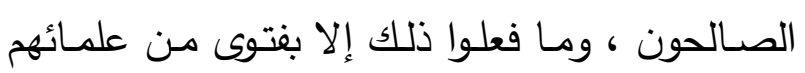

وأئمتهم وسائرهم «) (؟).

و يكفِّر -ابن حمزة- أكثر الأمة بناءً أن من لم يؤمن بقائم العترة فقد شتمه ، و من يشتمه فقد كفر : فيقول

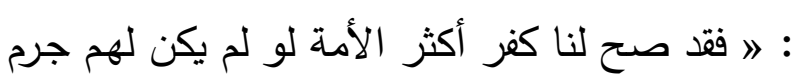

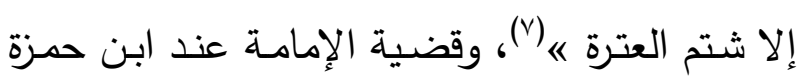
أخذت حيّزاً كبيراً ، وجعلته

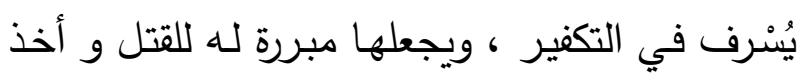

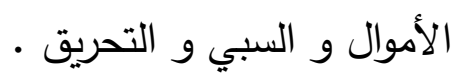

\section{المطلب الثاني \\ موقفة من الصحابة}

يرى الإمام الزيدي عبدالله بن حمزة أن الصحابة قد الصدابه

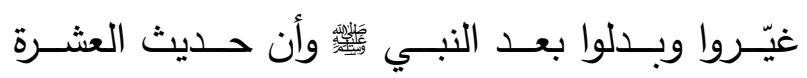
المبشرين بالجنـة شهادة حق ، وقول صدوق لوقل ، وإنما الثـأن في أنهم بقوا على تلك الطريقة التي استحقوا بها الجنة، أم غيروا وبدلوا؟ وقسّم العشرة على ثلاثة أقسام :

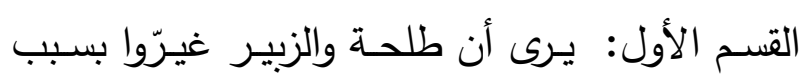
خروجهم على علي رضي الله عنه. والقسم الثاني : من أقدم على أمور لا يؤمن كونها

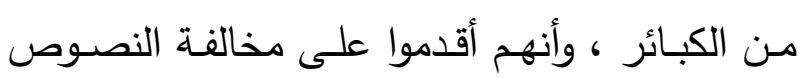

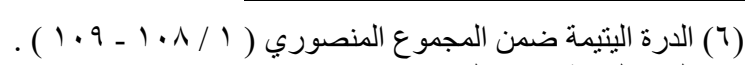

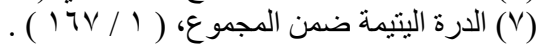

حـرب، ولا خــلاف فـي ذلــك بــين القاســية (1) والناصرية(广) واليحيوية (广) ، وهو قول جميع علماء

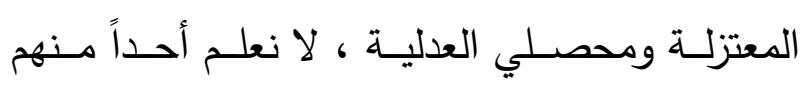
يخالف في ذلك «ـ(ء) . وينسب هذا القول - تكفير من أثبت الصفات وخلق أفعال العباد - إلى أئمته ، وهم رؤوس أئعة الزيدية

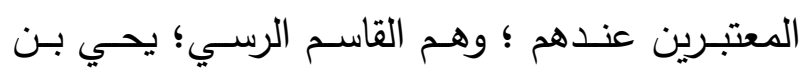

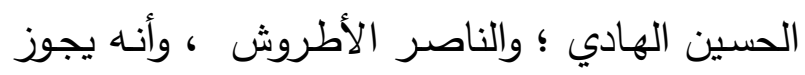
قتلهم وسبي ذراريهم ، فيقول :

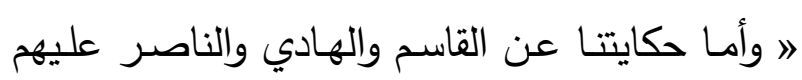

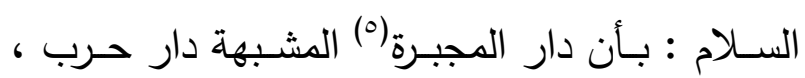

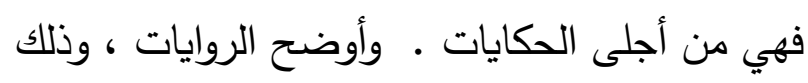
أن رواتها أئعة وعلماء لا يمكن حصرهم في رسالتنا

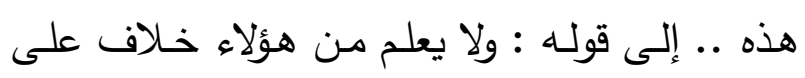
اختلاف أغراضهم وهم ألوف لا ينحصر أعدادها إلا فيلاه لخالقها في جواز غزو المجبرة والمشبهة والباطنية،

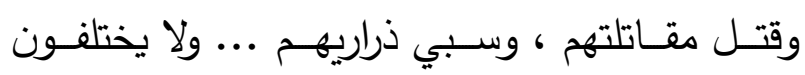

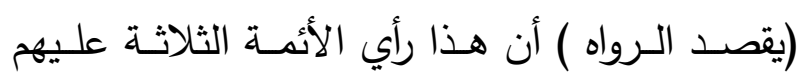

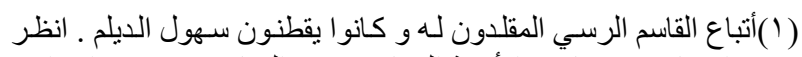

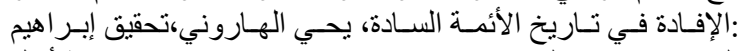

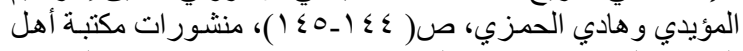

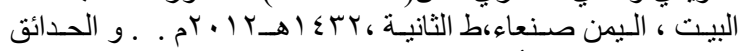

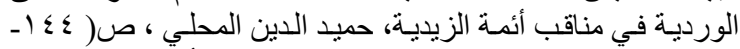

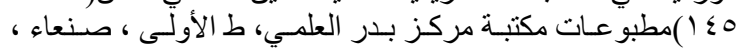

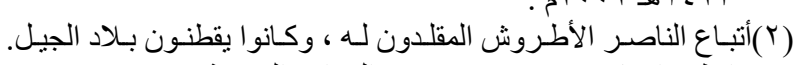

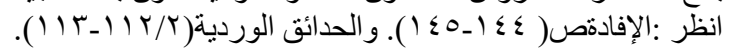

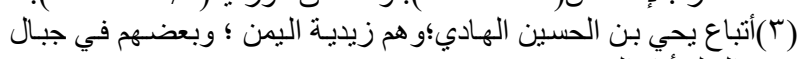

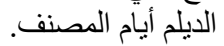

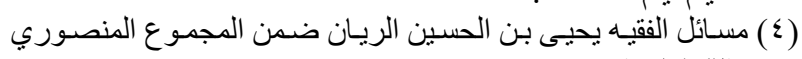

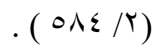
(0) المجبرة عنده مثبنو ا خلق أفعال العباد . ماك. 
بكر و عمـر لا نرضّـي عنهمـا و لا نسـبهما؛ لأن

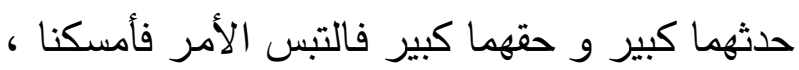
و أما الترضية عليهما فذلك من الرواة و أكثرهم من الن التهنيز

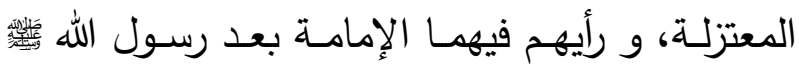
فكيف إلا الترضية. و أما رواية ترحُم علي عليهما فلم تصح فإن صحت

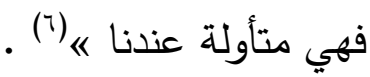
و هو هنا لا يترضى عن الثيخين ، و يرى عدم

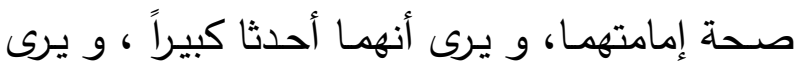

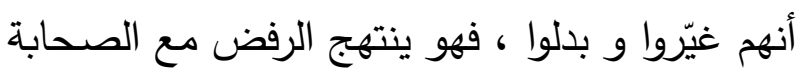

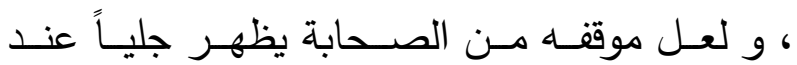

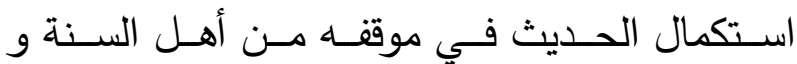

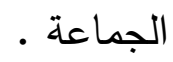
المطلب الثالث

\section{موقفه من أهل السنة والجماعة}

إذا كان ما رأينا -في المبحث السـابق - من موقف هونف ابن حمزة من الصحابة ، فكيف يا ترى يكون موقفه من أهل السنة والجماعة الذين يسيرون على إثرهم؟! لقد ذهب الإمام الزيدي عبدالله بن حمزة في مغالاته إلى تكفير كل من لا يعتقد بالإمامة على ما ذهب لهب إليه هو ، ويعد ذلك شتماً لآل البيت ، وشتمهر كفر بالامنيه عنده، فيقول : 》 وقد روينا بالإسناد الموثوق به إلى لى له

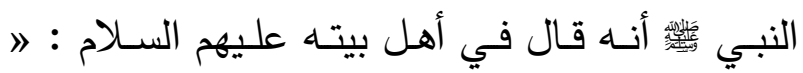

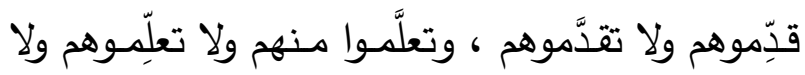

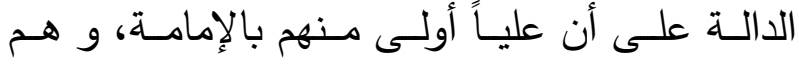
المشايخ الثلاثة أبو بكر وعمر و عثمان -رضي الله عنهم وإن رغم أنف الكاره-. و القسم الثالث : يقطع على كونـه من أهل الجنة ، وهو من كان معصوماً لا يواقع كبيراً بعد ذلك المقام ، و ذلك علي بن أبي طالب رضي الله عنه (') .

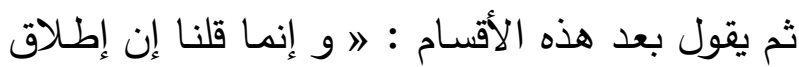

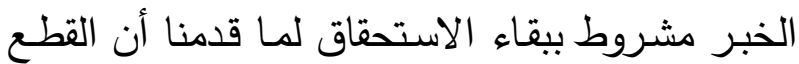

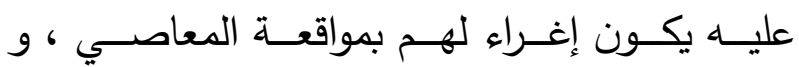
الإنهماك في اللذات ، لما في ذلك من النفع العاجل

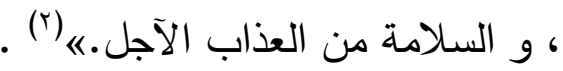
و يكفّر معاويـة -رضـي الله عنـه-؛ و كفّر أصحابه

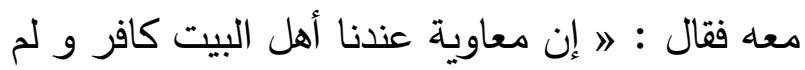
يُعلم في ذلك خلافاً من سلفنا الصالح ... إلى قوله : و حكم أصحابه كحكمه بلا خلاف «" (r) .

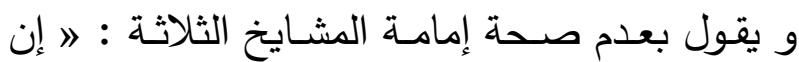
ولاية أبي بكر و عمر و عثمان غير صحيحة عندنا لا دليل عليها، و مـا لا دليـل عليـه لا يجوز إثباتهـ لئه

و يـرى أن عثمـان أحـدث قبيحـاً فيقـول : " و أمــا عثمان و إحداثه فلا شك في قبحها «" (0) .

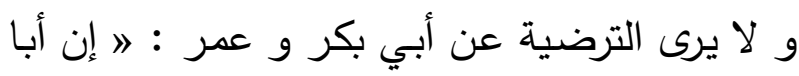

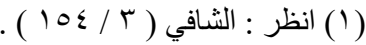

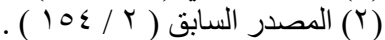

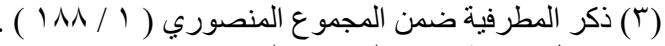

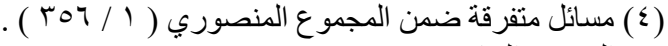

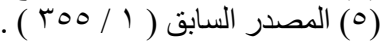


الحسنى ، وذلك في مقابل أصلي التوحيد والعدل ، و

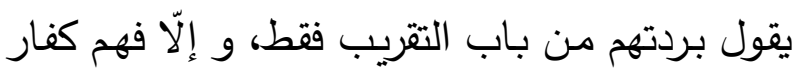

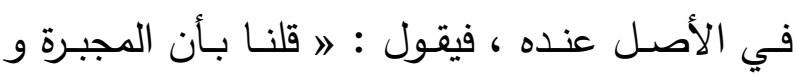
المطرفية و من جرى مجراهم كفّار أصلاًا ، و دارهم

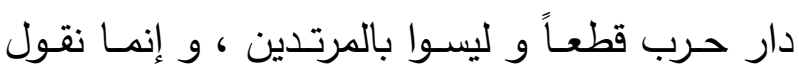

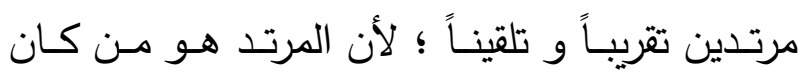
مسلماً فكفر ، و هؤلاء لـم يعرفوا من آبائهم وآبـاء آبائهم إلا الكفر لقولهم بالجبر و القدر ، و الإرجاء

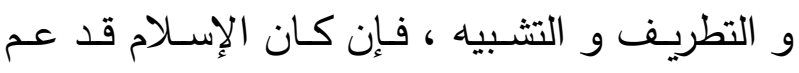

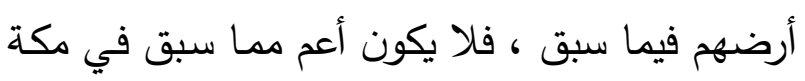
حرسها الله تعالى لأنها أرض قبلة لـونة أنبياء الله سبحانه

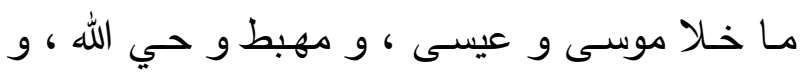

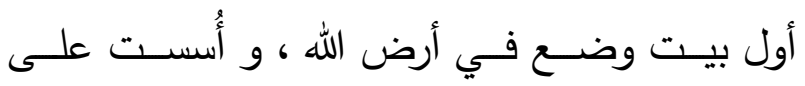

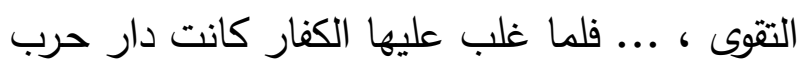

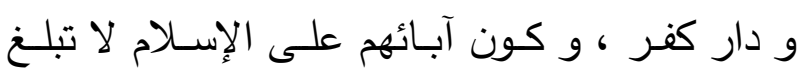

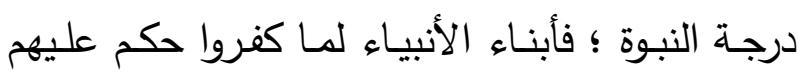
بالكفر ... فقد صسار من ذكرنا من هذه الفرق كافراً بالاتفاق من أكابر علماء أهل العدل، و كفره متوارث عن آبائه ، و الدار دارهم ، و الغلبة لهم ، فهي داري كفر مستبين ، و دار حـرب بيقين ، و إنمـا قدرنا

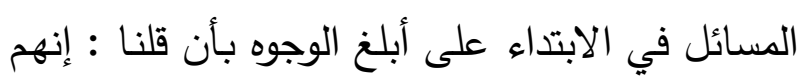

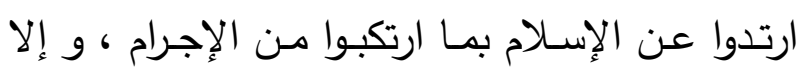

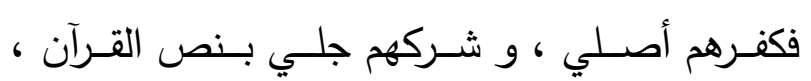

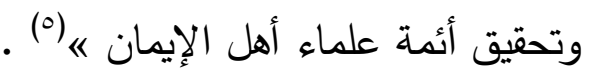
و يُنسب هذا القول إلى أئعته و طلابهم و شيعتهم الإيمان اله

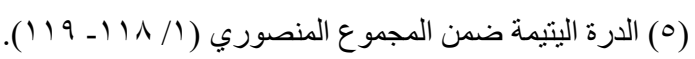

تخـالفوهم فتضــلوا ، ولا تثــتموهم فتكفـروا ه(1) ،

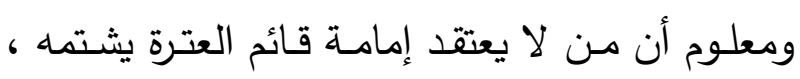

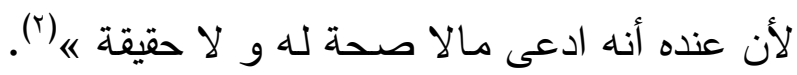
و معلوم أن أهل السنة و الجماعـة لا يقولون بقولـه لانه

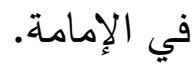
و يذهب بعيداً في هذا الاتجاه فيكمِرِ كل من اعتقد إمامة الأمويين و العباسيين : بعين في الاتهاه ״ لو لم يكن لهذه الأمة جرم في دين الله إلا موالاة بني أمية و بني العباس و اعتقاد إمامتهم ، و تتقليد

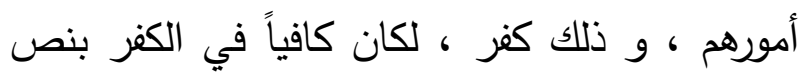

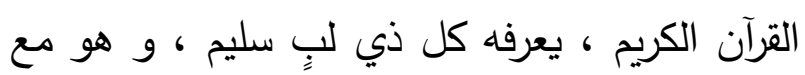
ذلك خلاف المعلوم من دين الرسول صلى الله عليه

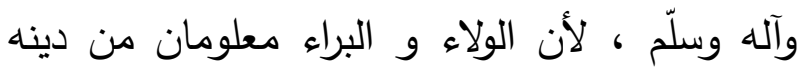

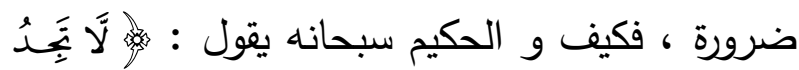

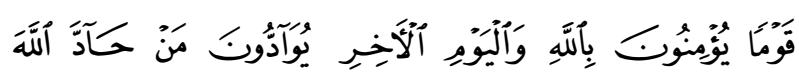

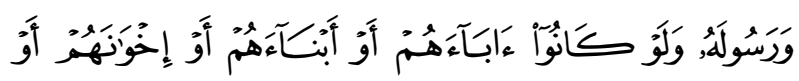

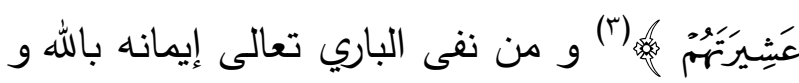

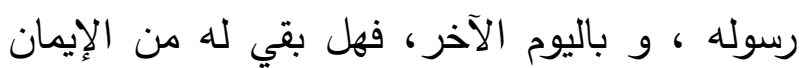

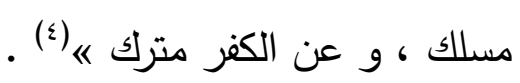
فها هو ينزل الآيات التي نزلت في أهل الكفر الأكبر الصراح فيمن خالفة في قضية الإمامة .

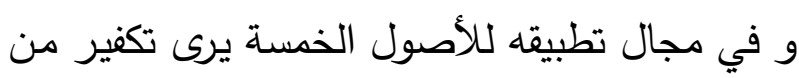

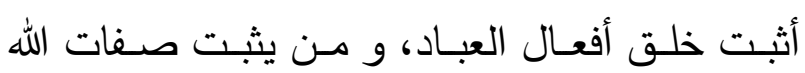

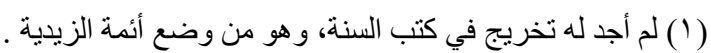

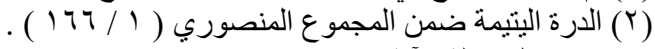

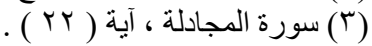

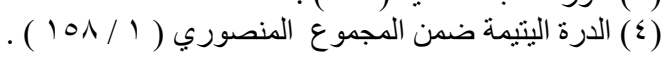


يسفك دماءهم و يهنك أستارهمب(؟). كذلك فإن أخاه الأمير يحيى بن حمزة سبى ست مئة سبية من نساء صنعاء ، واقتسموهن في قاع طيسان ، و قـال عبـد الله بـن حمـزة : 》 أمـا البِّباء فـنحن الآمرون به « لأن أهل صنعاء في نظره من المجبرة والمشبهة ، و أن حكمهم حكم كفار التأويل ما داموا لها لها تحت حكم الأيوبيين، و ليسوا تحت حكمه(r). و قد فرض الأعشار و الخراج و الخمس على كثير

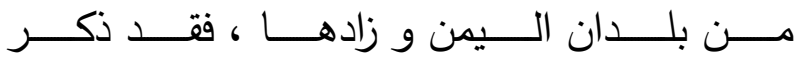
يحيى بن الحسين في أنباء الزمن عند ذكر محمد بن نشوان قال : 》 غير أنه -أي محمد بن نشوان - أنكر على الإمسام أمسوراً كثيرة ، منها مسألة الأعشـار التي

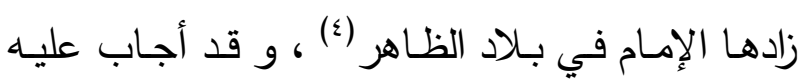
الإمام بقوله : و لو علمنا من أهل الظاهر الكفاية و الحماية مـا كان لنا في أخذ المال منهم غرض ، و و نحن لا ندّخره ، و لا نستنفع به لخاصسة نفوسنا ، و مـع ذلك فقد رفضـوا الجهاد بأنفسهـم ، و لا يصـلح

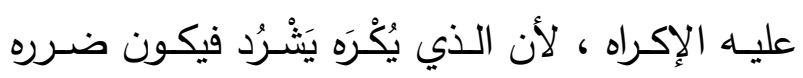

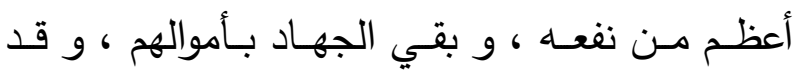
أمكننا الإكراه عليه ، و منها أن يكون عقوبةها(') . و ذكر الأكوع كذلك فقال : 》 و رأيت في هامش سيرة

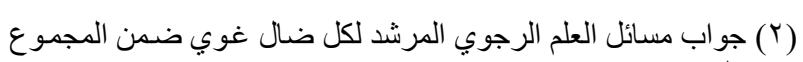

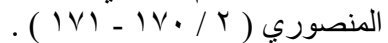

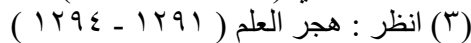

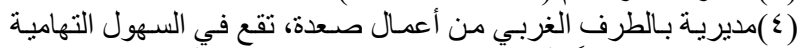

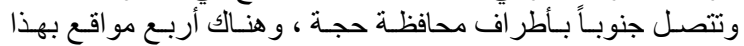

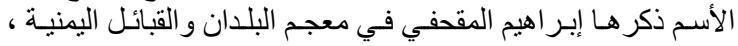

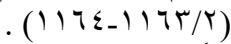
(0) نقلاً عن هجر العلم ص( (1) (1) ( ) ) .
مدا يدل على أن الزيديـة ينتهجون منهج الغلو في التكفير ، فيقول :

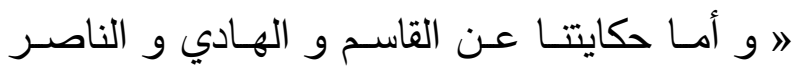

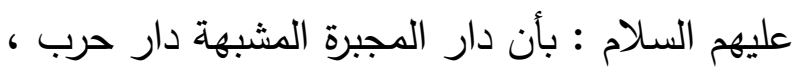

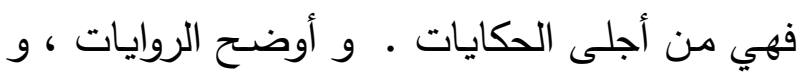

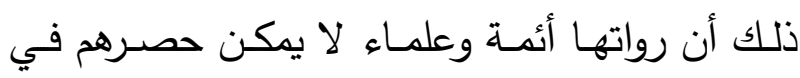
رسـالتنا هـذه .. إلـى قولـهـ : و لا يعلـم مـن هـؤلاء

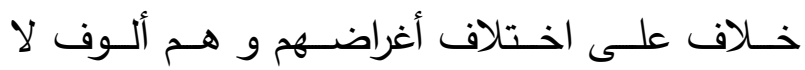
ينحصر أعدادها إلا لخالقها في جواز غزو المجبرة و المشبهة والباطنية، و قتل مقاتلتهم ، و سبي ذراريهم

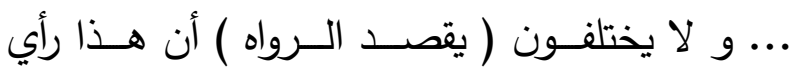

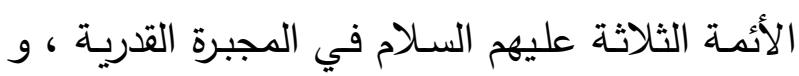

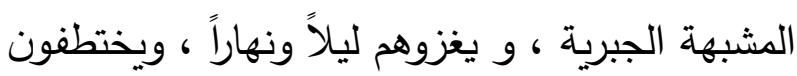

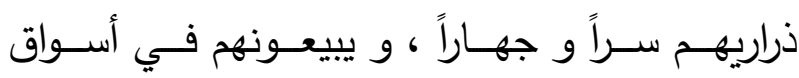

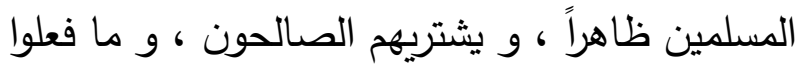
ذلك إلا بفتوى من علمائهم وأئمتهم و سائرهم «" (') . و يقول فيمن تشكك في أمر الإمامة سواء كان واحداً

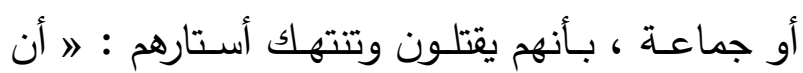

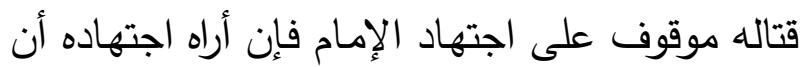

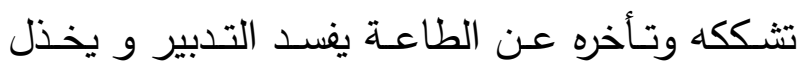

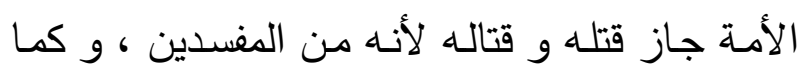
يجوز أن يتشكك جماعـة و أهل مخاليف ، فيسألهم الإمام الطاعة فيقولون : نحن متشككون فلا يخلّصهم ذلك عنــ أهل العلم ، لأن الشـك ليس بـدين ، بـل

$$
\text { ( (1) الدرة اليتيمة ضمن المجموع المنصوري ( / / • 1 ـ 9 ـ 1 ) . }
$$




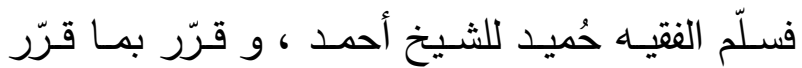
شيخه « (v) وقت انتهج مع مخالفيه التحريق و لا يرى حرمةً

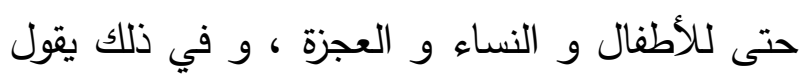

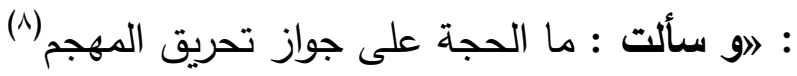

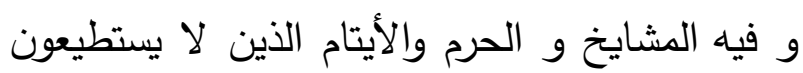

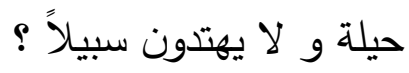
الكلام في ذلك : إن حريق المهجم (9)إنما كان لها قصدها جنود الحق و فيها جند الظالمين فلقوهم

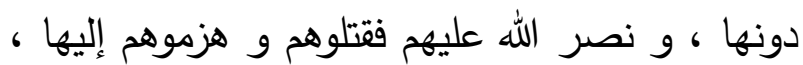

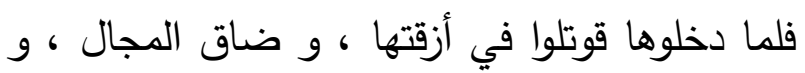

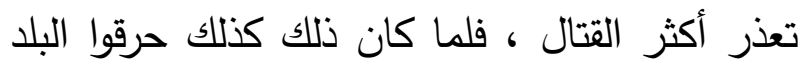
ليتصلوا بالعدو الظالم من غير قصد و لا مضرة

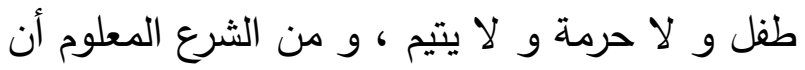

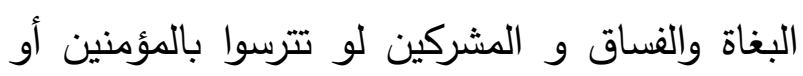
الأطفال أو النساء و لم يتمكن المحقون من قتلهم إلا بقتل الأطفال و المؤمنين و النساء لجاز ذلك الك الكن للمحقين قتلهم ليصلوا إلى أعداء الله الظالمين، فكيف إذا لم يقصدوا ، فهذا جواب على أغلظ حكم يكون علينا.

فأما إذا رجعنا إلى أن مذهب أهل البلد مذهب الجبر و القدر (·) ، و و علمنا أن بلاد الجبرية و القد القدرية عند القاسم و الهادي و الناصر عليهم السلام دار

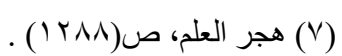

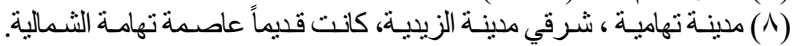

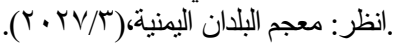

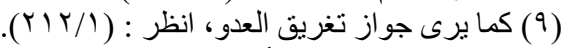
( · ( ) يقصد من يثبت خلق أفعال العباد .
الإمـام المهدي أحمد بن الحسين ما لفظه : مِنْ خط الفـ

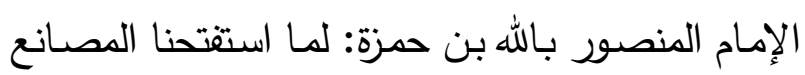

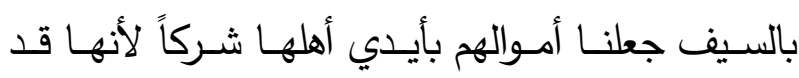
صـارت بحكم الله مِلكاً للمسلمين ، و و جعلنا لهم القيام

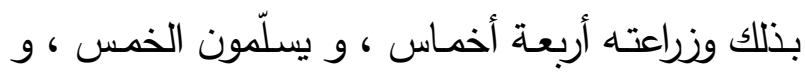

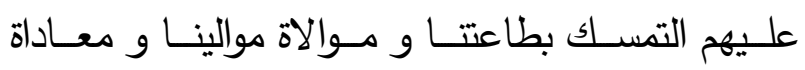

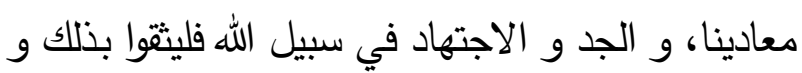
بالله الثقة «(') . (1) و في هجر العلم : \ قـال الفقيـه الإمـام حُميد بـن

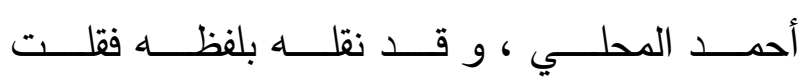

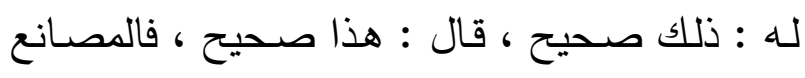

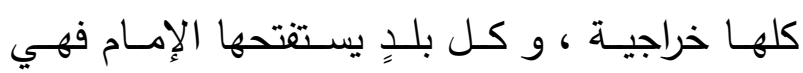
خراجية «ا (r).

و روى السيد الحسن بن علي بن حمزة قال: مولانا

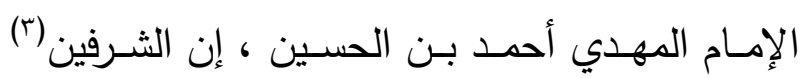

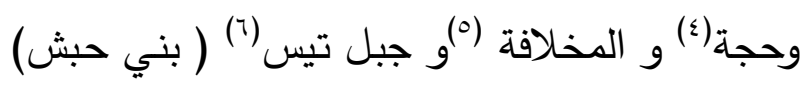
و المصـانع كلها خراجية، قال : و سمعت الثيخين

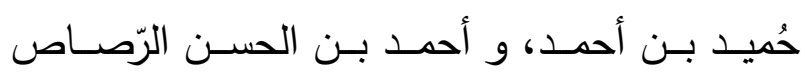

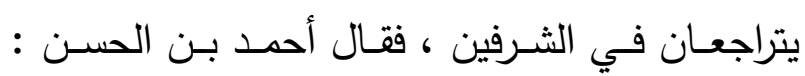

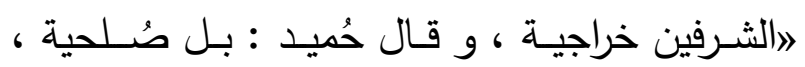

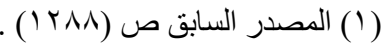

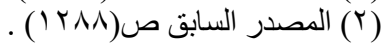

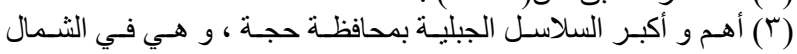

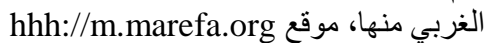

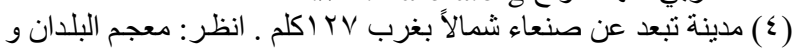

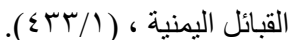

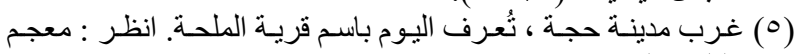

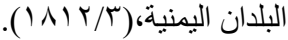

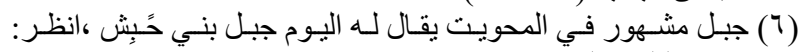

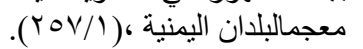


هذه الفرق كافراً بالاتفاق من أكابر علماء أهل العدل

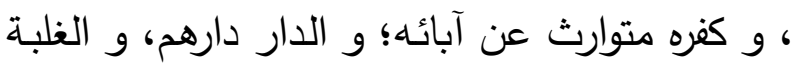

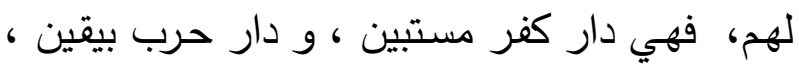

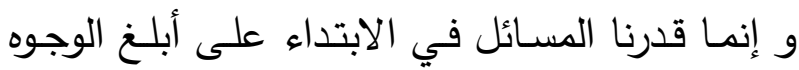

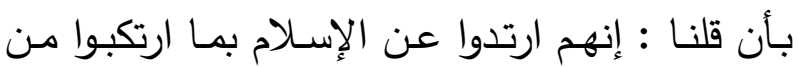

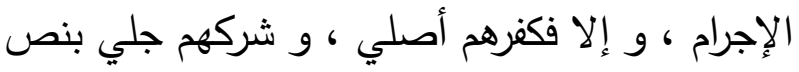

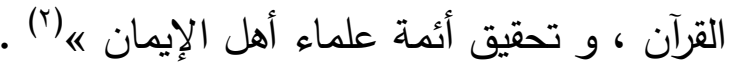

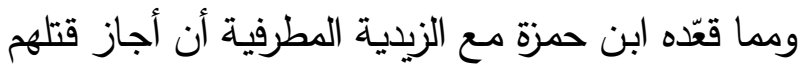

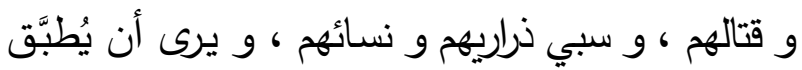

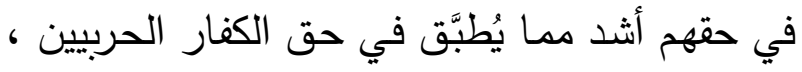

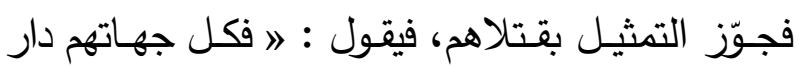
حرب يحل فيها قتل مقاتليهم ، و سبي ذراريهم و نسائهج

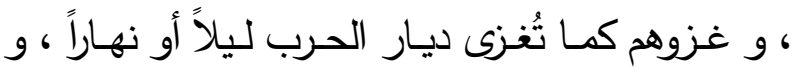
أخذهم سراً و جهاراً ، و القعود منهم كل مرصد؛ و و قد

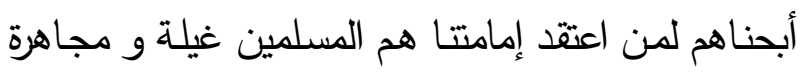

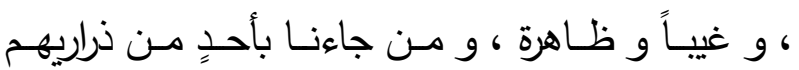

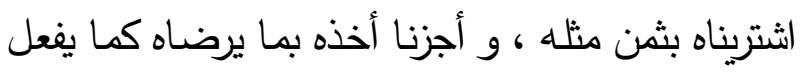

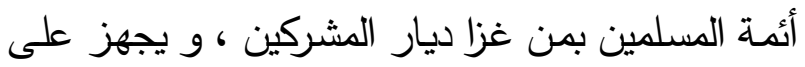

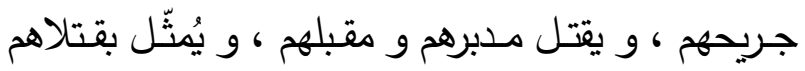

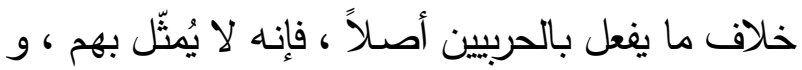

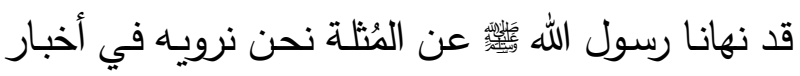

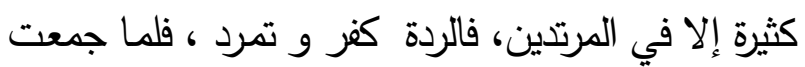

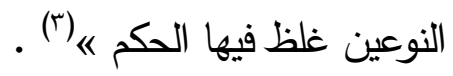
كما يكفِر من الزيدية مَنْ يوالي من خالفه في الإمامة و
حرب لا يختلفون في ذلك ، و لا يختلف أتباعهم من أولادهم سلام الله عليهم و شيعتهم رضي الله عنهم في ذلك ، و معلوم أن دار الحرب لا يتوجه فيها هذا

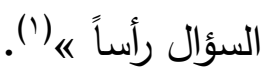
وهكذا يتضح جلياً غلو ابن حمزة في أمر الإمامة ، وانتهاجه العنف ضد كل من لم يُقر بها على الوجه الذي يراه ، فقد كثّر الأمة بسبب عدم اعتباد أنها واجبة في البطنين ، و يضيف لذلك تكفير من لم يعتقد اعتقاده في التوحيد والعدل على مذهب المعتزلة

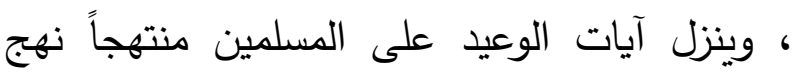
الوعيدية في ذلك ، فليس عنده إلا مؤمن أو كافر . المطلب الرابع

\section{موقفة من مخالفيه من الزيدية}

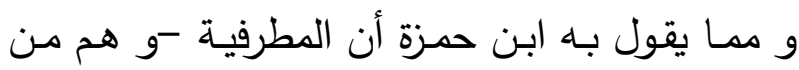
الزيدية- كفّاراً لكونهم خالفوه في شرط البطنين في الإمامة ، فلا يرونه شرطاً فيها، و يجعل دارهم دار حرب، و يقول بردتهم من باب التقريب فقط؛ و إلا

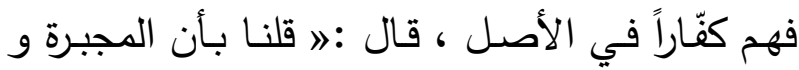
المطرفية و من جرى مجراهم كفّاراً أصلاً ، و دارهم

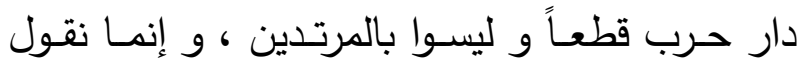

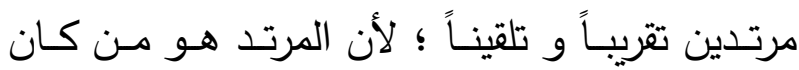

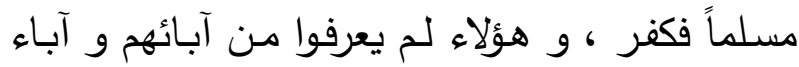
آبائهج إلا الكفر لقولهم بالجبر و القدر ، و الإرجاء

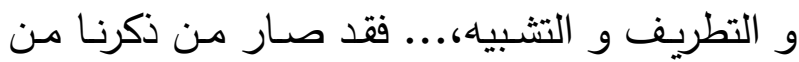




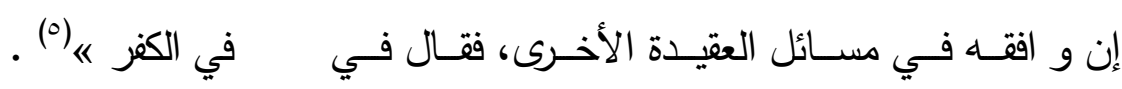
و يغلوا في تكفيرهم إلى أن جعل المطرفية أشد من

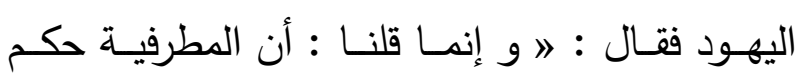

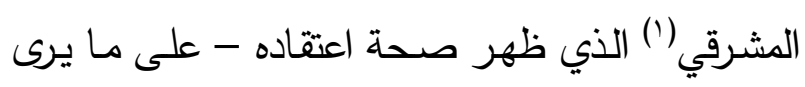
الزيدية - إلا أنه يميل للمطرفية : 》 فأي صحة اعتئية اليهود لأنـا و جدنا فيهم صفة اليهود و زيـادة في اليهال

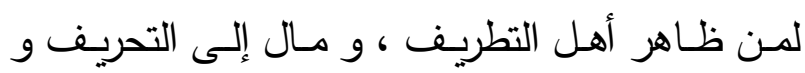
الكفر «( ) و بلغ به الأمر إلى أنه كفّر بالإلزام من أنكر عليه

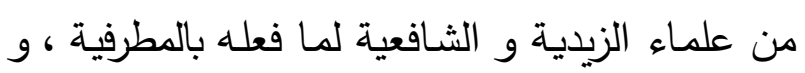

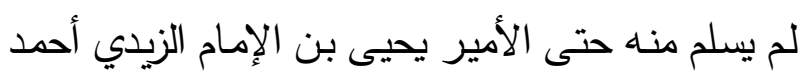

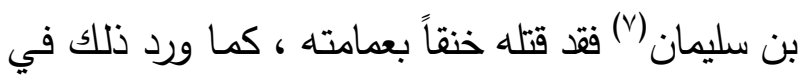
كتاب الفضائل لأحمد بن عبد الله الوزير (^) .

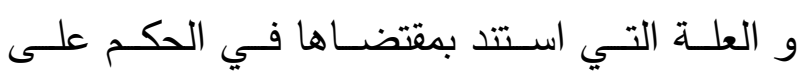
المطرفية بالفناء و الزوال هي العلة نفسها التي حكم

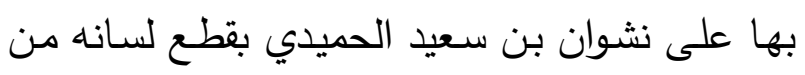

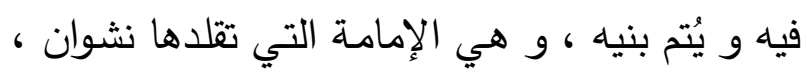

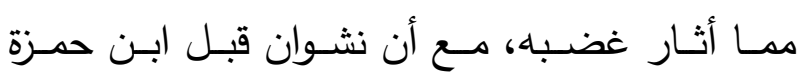
بسنوات، فقال فيه :

أما الذي عند جدودي فيهه فيقطعـون لســـه مسن فيـهـ

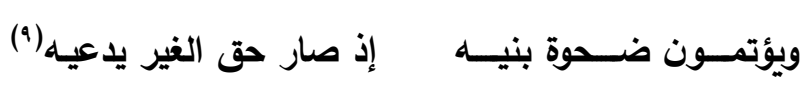
و ردّ عبد الله بن حمزة على محمد بن نشوان حينما

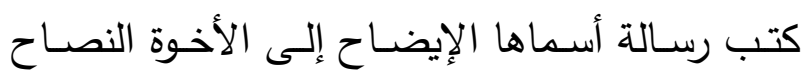

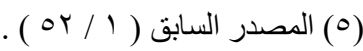

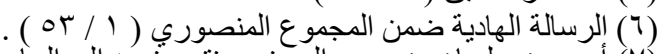

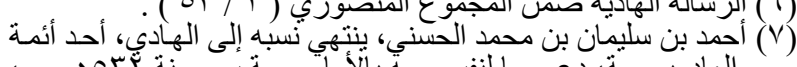

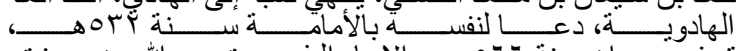
توفي بحيدان سـنة دانة

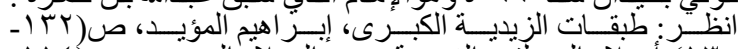

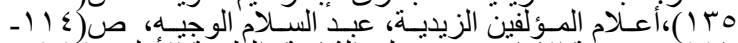

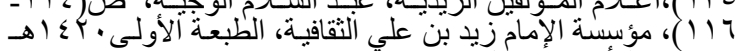

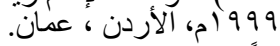

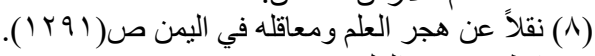

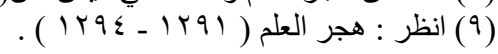

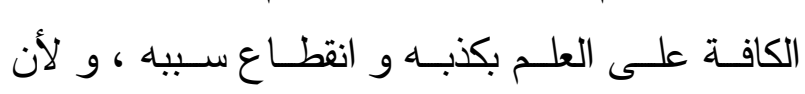

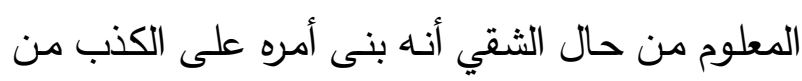

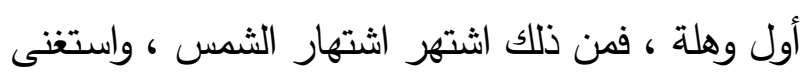

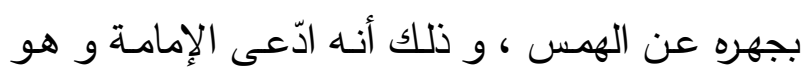

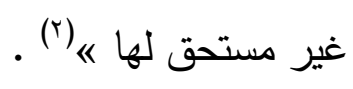
إلى قوله : او هو يكون و الحال هذه كافر لموالاته هئه

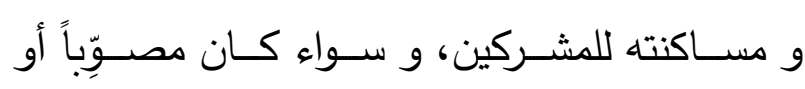

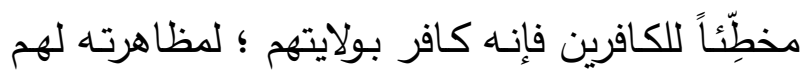

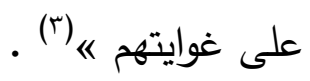

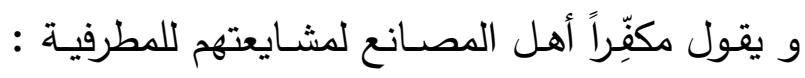

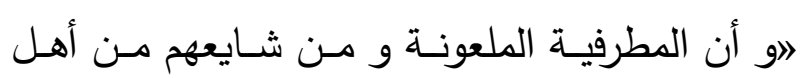

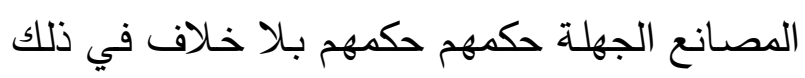
؛ و أن ردتهم بوجوه كثيرة أقوال أهل الفرق الثلاث

$$
\text { داخلة في بعض أقوال هؤلاء «ـ(؟). }
$$

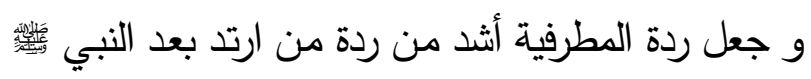

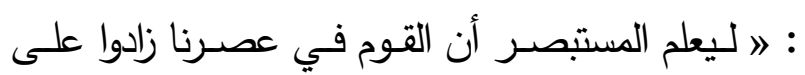

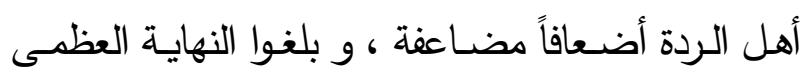
(1) هو: محمد بن منصور بن المفضل بن الحجاج قام مع المطرفية من

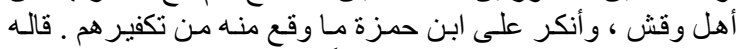

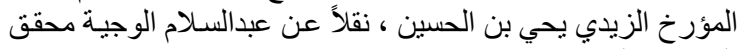

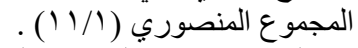

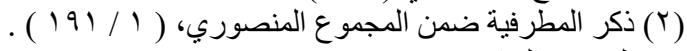

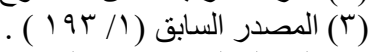

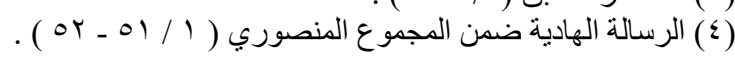


يشهد أن لا إله إلا الله و أن محمداً رسول صلى الله عليه وآله وسلم عبده ورسوله غير مستكثر لنا ؛ لأن أبانا علي بن أبي طالب عليه السلام هو إمام الأئمة، و سيّّ الأمة ، ووصي رسول ابلي الله صلى الله عليه وآله وسلم، و الإمام المعصوم ، و شبيه هارون الاهن ، والمنصوص عليه يوم الغدير ، ما قتل بعد رسول الله صلى الله عليه وآله وسلم إلا من يشهد ألا إله إلا بلا الله و أن محمداً عبده ورسوله صلى الله عليه وآله وسلم في الجمل و صفين و النهروان ، بل هم من الصحابة و التابعين الذين ورد فيهم عن رسول الله صلى الله عليه وآله وسلم الآثار الثريفة .. و أمّا من أظهر البراءة منهم و اعتقاد الإمامة بعد القدرة عليه ، فإن غلب على الظن أن إظهار ذلك تديناً و خوفاً لله

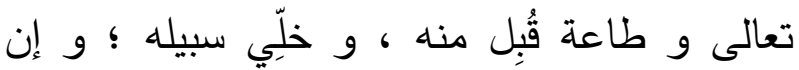
غلب في الظن أنه منه تفاد من القتل و السباء ، لم

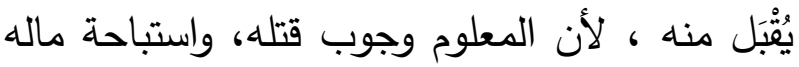

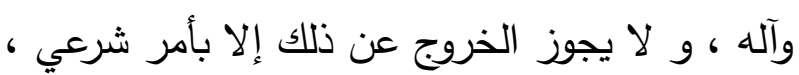

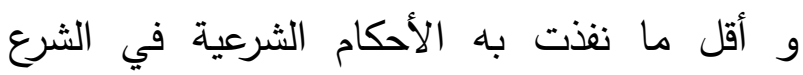

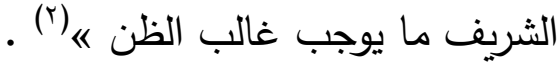
و بلغ من غلوّه أن أفتى بتكفير مَنْ وُجِدَت من من النساء في ديار المطرفية ولو كانت ليست منهم ولا

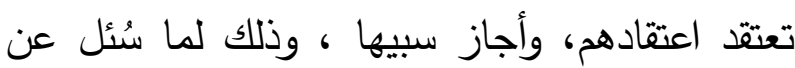
من وُجدت في ديار المطرفية سواء كانت من أهلها

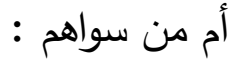

ذكر فيها عدم شرطية النسب للإمامة، برسالة أسماها الإيضـاح بعجمـة الإفصـاح ، قـال صـاحب السيرة المنصورية : " و صعد الإمـام المنبر و ذكر طرفاً

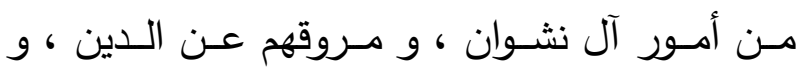

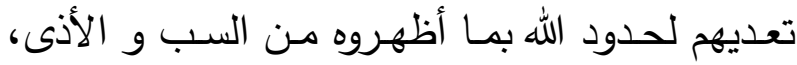
والهجو بالأشـعار لأهل البيت عليهم السـلام جريـاً

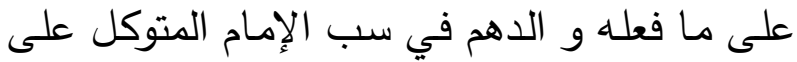

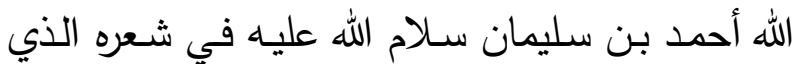

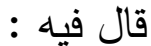

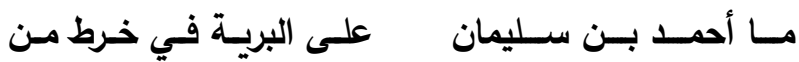

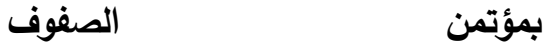

و كان من حضر الجمعة من زبيد حى من خولان ... و فيهم رجل يُسـى حسن بـن يحيى مـن قريـة

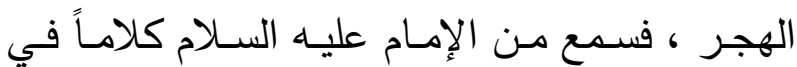

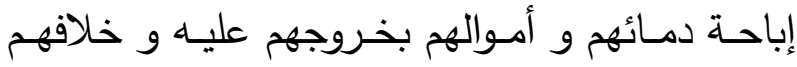
أمره. و كانوا يرون بجواز الإمامة في الناس عموماً

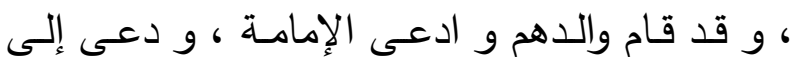

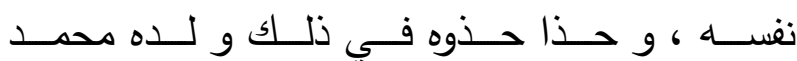
هذا ، فذهب ذلك الرجل إلى بلاده و قد و طُّن نفسهـ على قتله، و التقرب بذلك إلى الله ... الخ هـ (') .

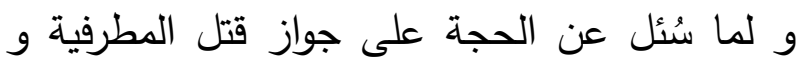
هم يشهدون ألا إله إلا الله و أن محمداً رسول الله هوله له

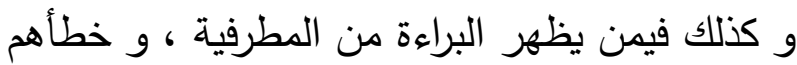
في الإمامة بعد القدرة عليه؛ قال :» إن قتلنا لمن إن إن 
فقد سُئل عنهح ، فقرّق بين متقدميهح ومن كان يعيش

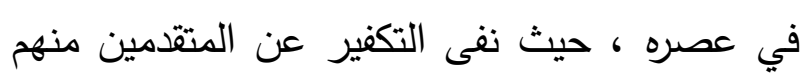
استتاداً على الأثر الذي ثبت عن علي علي رضي الله عنه و الذي نفى عنهم الكفر ، و لكنه كفّر من كان

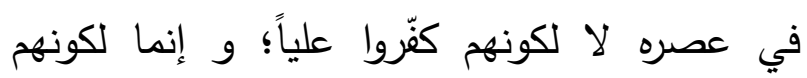
يُشبتون صفات المولى عز وجل و يثبتون خلق أفعال العباد ، " و سألت : عن الخوارج هل يكونون كفاراً

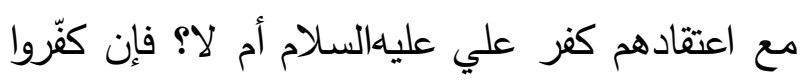
فما الحجة؟ أو لا فما المانع؟ كعي علئ

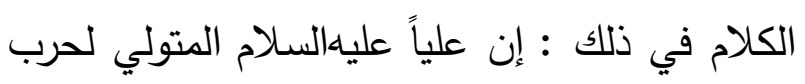

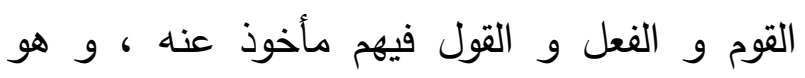

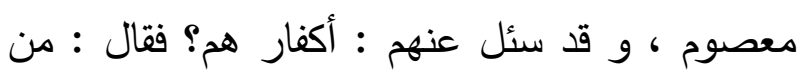

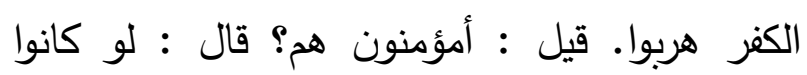

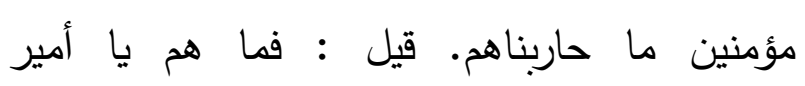
المؤمنين؟ قال : إخواننا بالأمس بغوا علينا فقاتلناهم حتى يفيئوا إلى أمر الله (؟). فلو لا قوله هذا لقضينا بكفرهم فلا يحكم بكفر سلفهم المر الهر

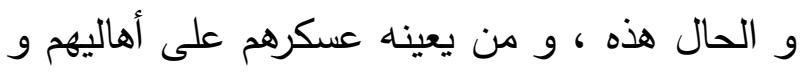

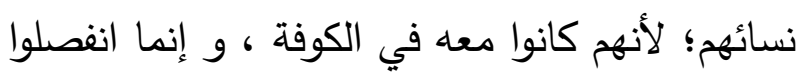
من عسكره وهو صادر إلى الثام لحرب معاوية.

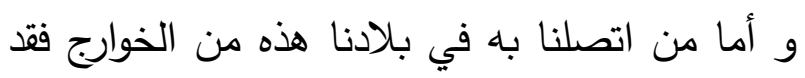

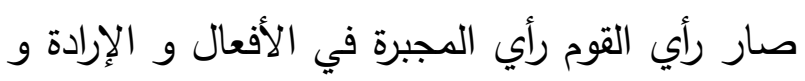

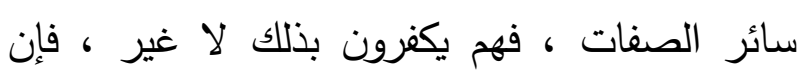

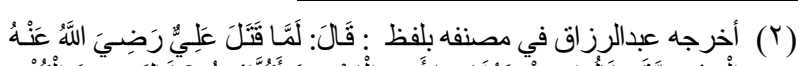

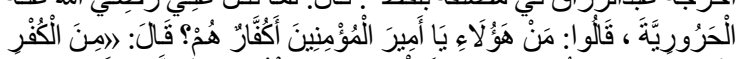

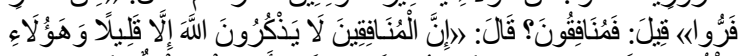

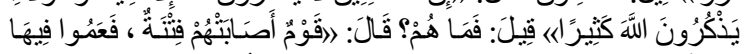

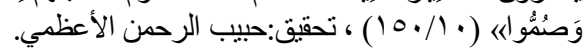

الاوسألت : عن حكم المرأة التي تكون في المصانع

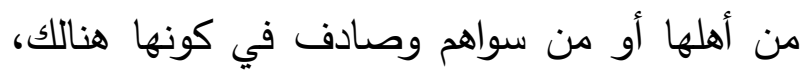
وهي تعتقد الحق ولا تحب المطرفية، ولا تعرف اعتقادهم هل يجوز سبيها؟ الكلام في ذلك : إن المرأة التي تكون من أهلها حكمها

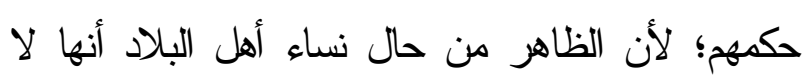

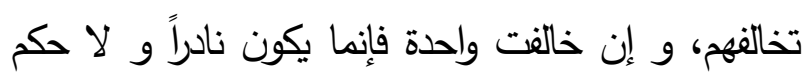
للنادر ، فإن علم من حالها أنها مخالفة للمطرفية في اعتقادهم فلا يخلو: إما أن تكون متمكنة من الهرب أو غير متمكنة ، فئول

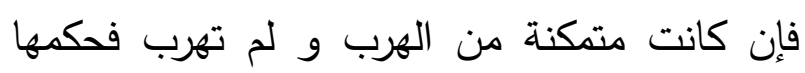

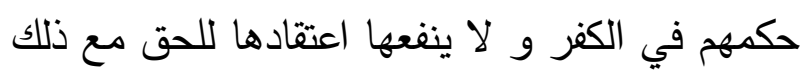

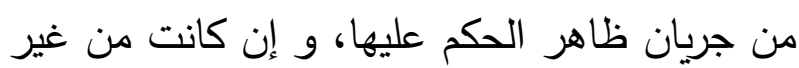
أهلها و جن جراءتهم مكرهة مغصوبة فحكمها حكم

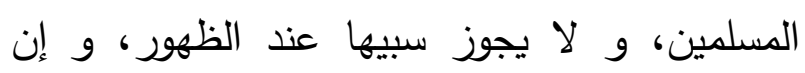
وصلتهم مختارة فحمها حكمه و كفرت بذلك.

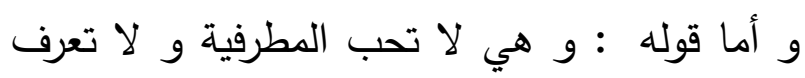
مذهبهم؛ فهذا كلام متتاقض كيف تبغض تدينا أو لو توله

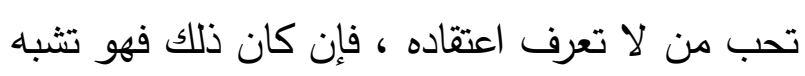

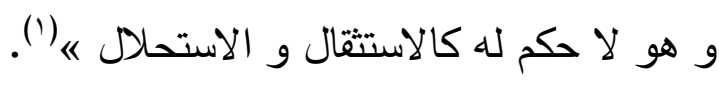
المطلب الخامس

\section{موقفه من الخوارج}

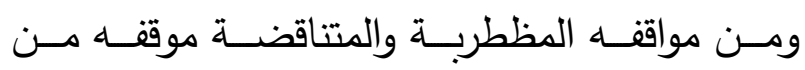
الخوارج، وهذا ديدن أهل الأهواء ، لا يكادون ينفكون والتهن

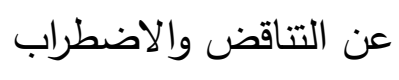
(1) ذكر المطرفية ضمن المجموع ( 197/1 (197/ ) . 
من العبيديّة الإسماعيلية الباطنية «(؟) . و يـرد على الفقيـهـ يحيـى البحيـري الــي كتب لـه يُعرِِّض في مصـافاته للسـلاطين مـن آل حـاتم مـن الباطنية ، فأجابه بكتاب وفيه :

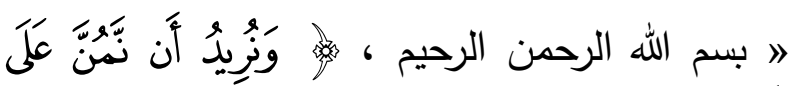

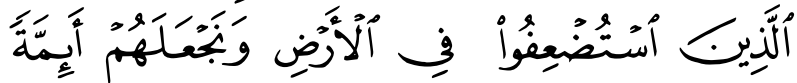

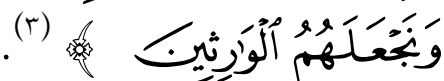
ألم تر أن الله أظهِّر دينه

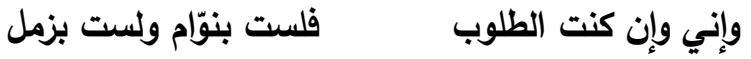

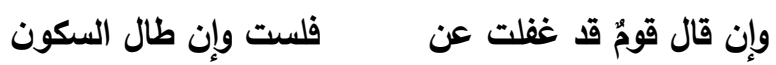

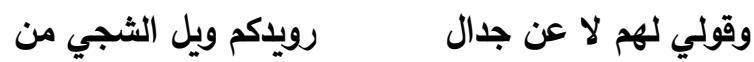

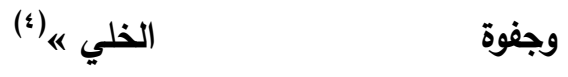

ويحكي صـاحب سيرته علاقته الحميميـة بالسـلاطين من آل حاتم ، و اهتمامه بهم واهتمامهح به ، و يذكر

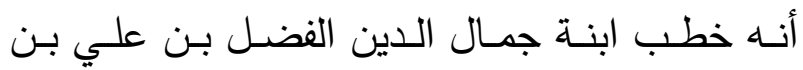

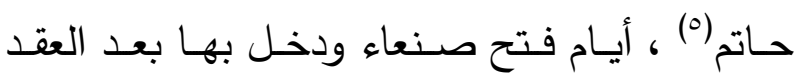

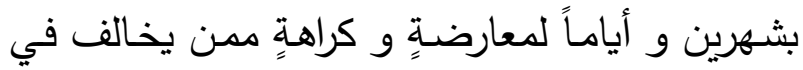
المذهب من النساء و الرجال ، و كان دخوله بها في العشر الأواخر مـن المحرم أول سـنة تسـع وتسعين ولين

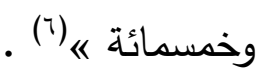
و لم يذكر خلافه مع الباطنية و تكفيره لهم إلا نادراً في عرض نكره للمخالفين لله ممن هم لا يصلون إلى شيء

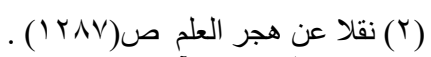

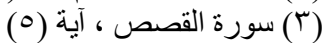

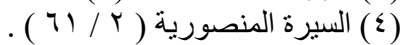

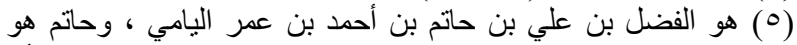

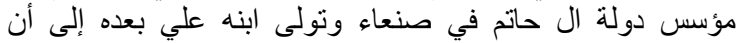

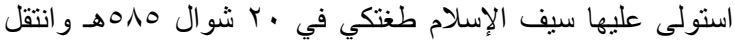

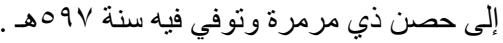

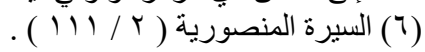

تابوا عنه كان حكمهم ما قدمنا «" ('). فانظر إلى هذا التناقض في قبول النص أحياناً و رفضه أخرى ، و كيف استحل دماء و أموال و نساء و ذراري المطرفية و هم منهم لكونهم انكروا شرط الأمامة في البطنين ، و لم يكفّر هولاء مع أنهم قاتلوا علياً -رضي الله عنه- و كفّروه ، و لعله لم يكنّر هولاء بذلك -أي انكارهم إمامة علي ، وإنكار أن تكون الإمامة في العترة - لكونهم ليس لهم شوكة بالقرب منه -في وجهة نظري-، فخالف منطلقاته لكونها تعارض أهوائه ، و إلا الأولى به و الأجدر أن لو استند إلى أثر علي -رضى الله عنه- في عدم

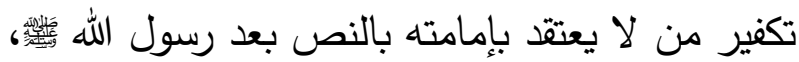
و عدم إنكار صحة إمامة الشيخين رضي الله عنهما، وعدم التتقص من الصحابة - رضي الله عنهم

\section{المطلب السادس موقفه من الباطنية}

مع مـا رأينا من شدة عبدالله بن حمزة مـع المطرفية الزيديـة و الشـافعية و الإيـوبيين إلا أنـه متصـالح مـع الباطنية أصحاب الكفر الصُّراح و الزندقة المريعة و العيـاذ بـالله ، فيقول الهـادي بـن إبراهيم : 》 و كان بينــهـ و بـين السـلاطين مسن بنـي حساتم اخـتلاطـو مصاحبة و مصالحة حين صساهرهم و تزوج منهح ، و لله مراثي في من مات منهم في أيامسه ، مـ أنهم 
الأصول الخمسة ، وزاد عليهم أن جمعها كاملة في مصنف واحد و أدخل فيها الإمامة.

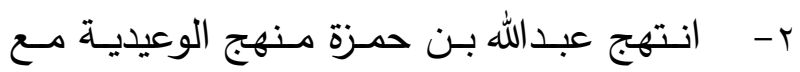

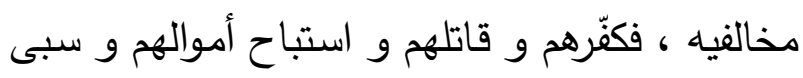
نسائهم و ذراريهم ، بما لم يُسبق اليه.

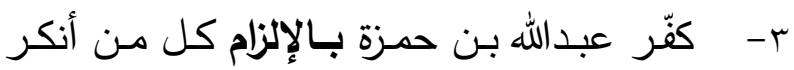
عليه ، أو لم يوافقه في اعتقاده .

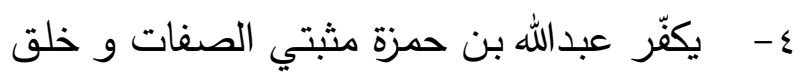
أفعال العباد ، و يرى حل دمائهم و أموالهم و نسائهح

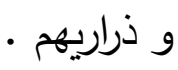
ه- - ينتهج عبدالله بن حمزة الرفض في عقيدته في

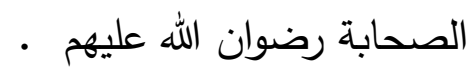
1- يقول ابن حمزة ببطلان خلافة الثلاثة : أبي بكر و عمر و عثمان رضي الله عنهم • - - - كفّر عبدالله بن حمزة فرقة المطرفية من الزيدية لكونهم لا يرون شرط الإمامة في البطنين، و أجاز تحريقهم. ه- عبـدالله بـن حمـزة يكفّر كل مـن لــ يحصـر الإمامة في البطنين. 9- يكفّر ابن حمزة كل مَنْ صحّح خلافة الأمويين

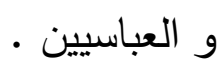

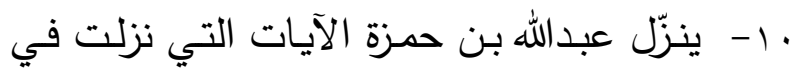

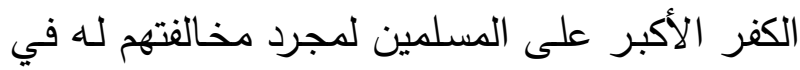

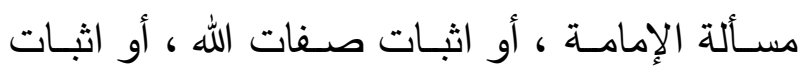

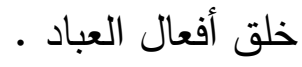

من أقوال الباطنية ، و يذكرهم عَرَضاً دون التأكيد عليهم ، ويثّي على نكر المخالفين دون الباطنية ، فمما قال :

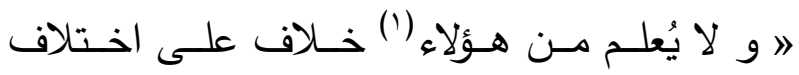
أغراضهم و هم أُُٔوف لا ينحصر أعدادها إلا لخالقها

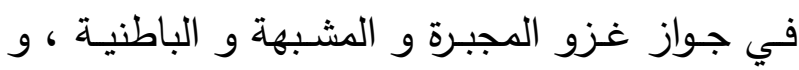

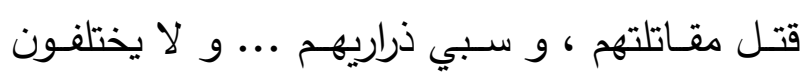

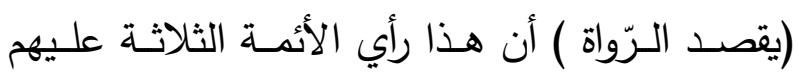

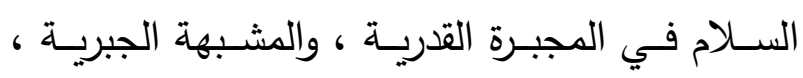
ويغـوهم لـيلاً و نهاراً ، ويختطفون ذراريهـم سـراً و

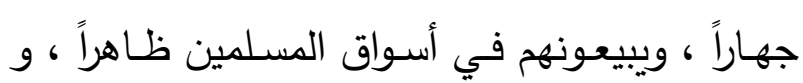

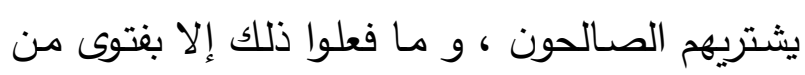

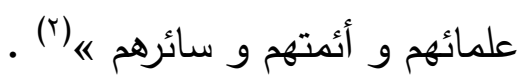
فوقفه هنا كان أكثر لطافة لكونه قد راحمهم وتزوج منهم ، وكذلك مما يدل على الود الذي كان يُظْهره

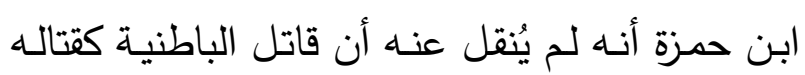

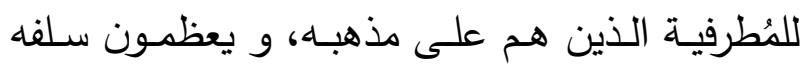
مثل الهادي و القاسم الرسي، و يستدلون بأقولهم ،

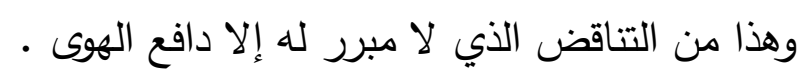
النتائج

الحمـــ الله والصــلاة والســلام على رسـول الله وآلـهـ

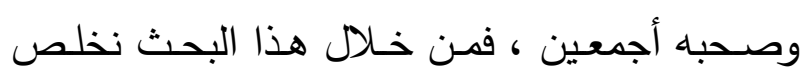
إلى مجموعة من النتائج و منها:

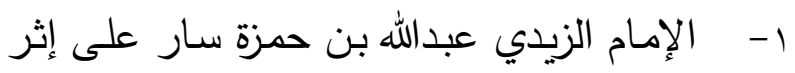

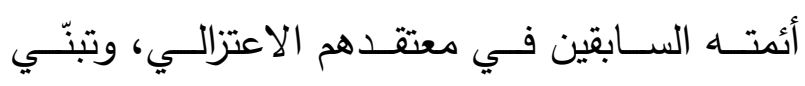

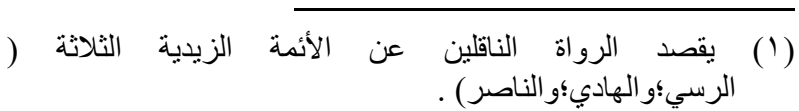

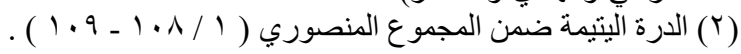


و لا دعي إلى سبي نسـائهم و ذراريهم ، مـع أنهم

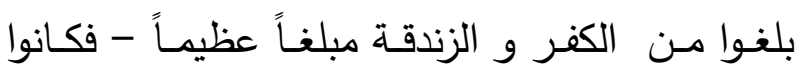

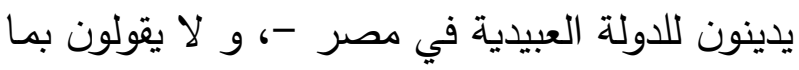

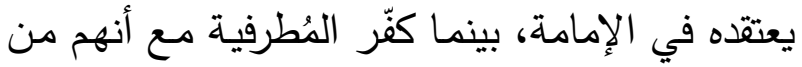

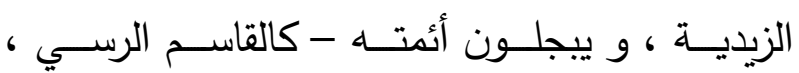

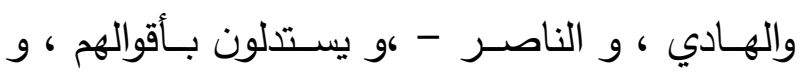
سبى نساءهم و ذراريهم و باعهم في الأسواق ، لأنهم يخالفونه في شرط البطنين فقط. التوصيات

أوصي بمزيد دراسة حول شخصية عبدالله بن حمزة وتأصيلة للعنف في المذهب الزيدي. - أوصـي بدراسـة الشخصـيات البـارزة مـن أئـــة الزيدية ليتضح لنا مدى الغلو الذي ابتدعوه و أصّلوه ، و خصوصاً من تمكن من الحكم و القيادة .

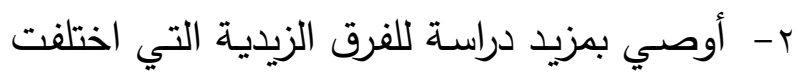

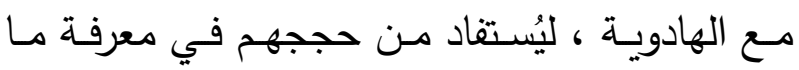
عليه الهادوية من الضالال و ردودهم عليهج •

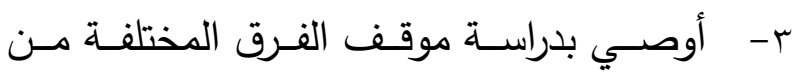
مخالفيها ، ليتضح المنهج الوسطي الذي ينتهجه أهل السنة من مخالفيهم •
11- توقف عبدالله بـن حمـزة في الخـوارج فلم يقل بتكفيرهم ، كونهم كفّروا علياً -رضي الله عنه- وقاتلوه ، و إنما كفّرهم لكونهم يشبتون الصفات أو خلق أفعال

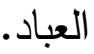

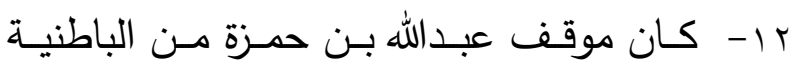
موقفاً لطيفاً لكونه تزوج منهم ، فلم يذكرهم في فتاويـه إلا في أقل القليل ، و لم يقاتلهم • ومن خلال هذه النقاط يتلخص لنا غلو الإمام الزيدي عبدالله بن حمزة في التكفير ، فقد كفّر المسلمين دون تفريق ، و دون النظر إلى ظوابط محددة و لا أدلة و

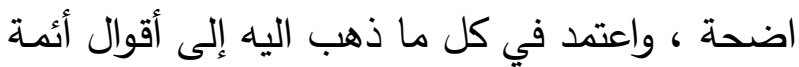

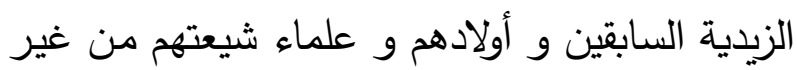
العترة ، و قد خص بالذكر القاسم الرسـي والهادي

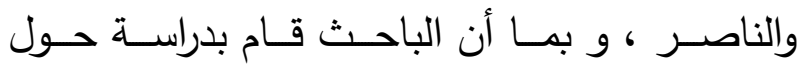
الشخصيات التي أشار اليها ابن حمزة فلقد فاق أئمة الزيدية الذين سبقوه شدةً في قضية تطبيق الأصول لفي الخين

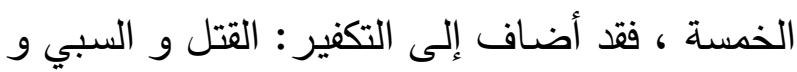

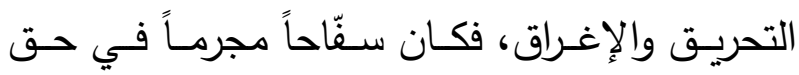

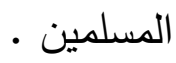
كمـا ظهر تتاقضـه في المنهج ، و ذلك مـن خـلال تكفيرة لمن لم يقل بإمامة قائم العترة ، و عدم صحة إمامة المشايخ الثلاثة ، و في نفس الوقت لا يقول بتكفير الخوارج الذين خرجوا على علي -رضي الله عنه - و لم يقولوا بإمامته وكفّروه. و يظهر تتاقضــه كذلك في تعاملـه مـع الباطنيـة، حيث لم يذكرهم إلا قليلاً ، و لم يعلن عليهم الحرب لهامل 
- - ذ ذكر المطرفيـة وأحكامهم وغير ذلك ، عبدالله بن حمزة ، ضمن المجموع المنصوري القسم الأول

^- الرسالة الهادية يالأدلة البادية ضمن المجموع المنصوري ، القسم الأول . 9- زبد الأدلة في معرفة الله ، عبدالله بن حمزة ،

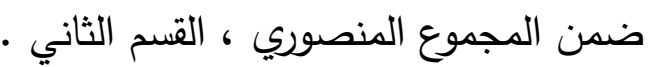

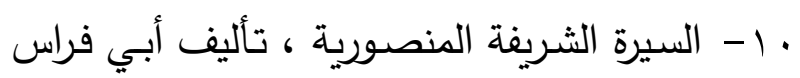
بن دعثم ، تحقيق : د. عبدالغني محمود عبدالعاطي

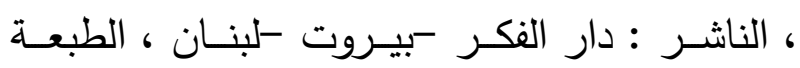

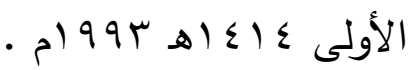

11 - الثافي ، عبدالله بن حمزة بن سليمان ، تحقيق

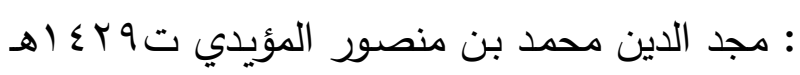
، منشورات مكتبة أهل البيت -اليمن -صعدة . مجندول r ا - طبقات الزيدية الكبرى، ويسمى بلوغ المراد إلى ، معلى

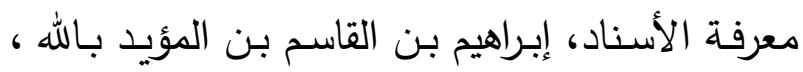

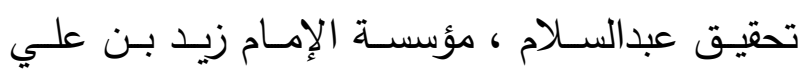

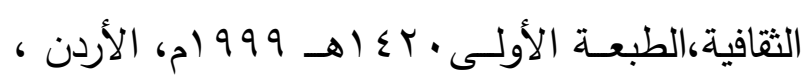

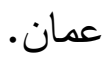

با - مسائل الفقيه يحيى بن الحسين الريان ضمن المجموع المنصوري، القسم الثاني ع ا - مســائل متفرقــة ضــمن المجمـوع المنصـوري

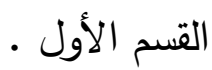

المصادر و المراجع

- - أعلام المؤلفين الزيديـة ، عبد السـلام الوجيـه،

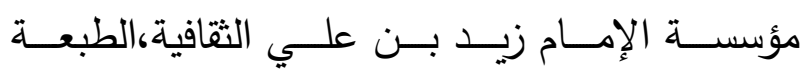

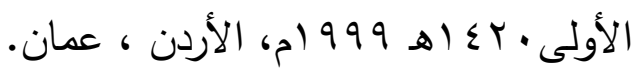
r- الإفـادة فـي تـاريخ الأئمسة الســادة، يحسي

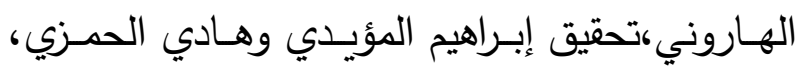

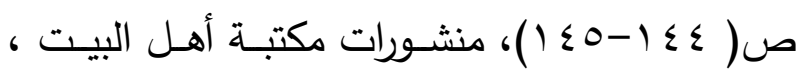

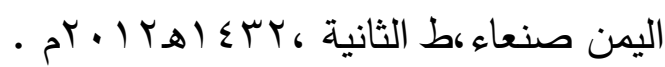
r- التحف شرح الزلف ، مجد الدين بن محمد

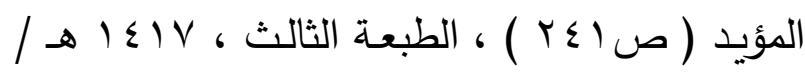

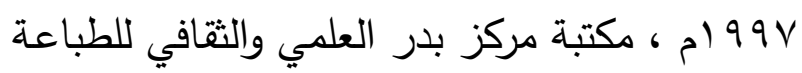

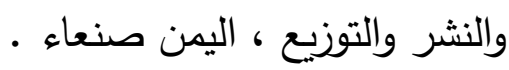
ع - جواب مسائل العلم الرجوي المرشد لكل ضـال

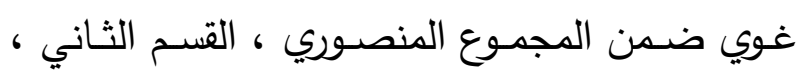

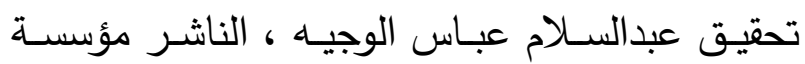
الإمام زيد بن علي الثقافية. ه- الحدائق الورديـة في مناقب الأئكـة الزيديـة ، حميد أحمد محمد المحلي ( / / r ) ) ، تحقيق د.

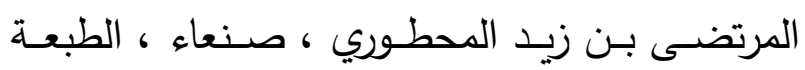

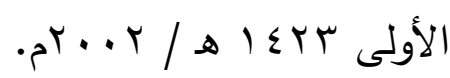

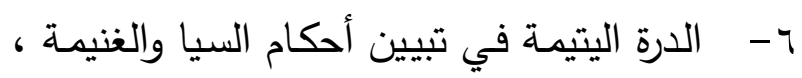

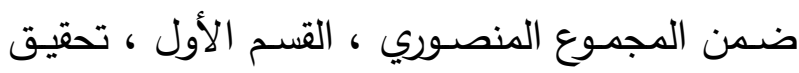
عبدالسلام عباس الوجيه ، الناشر مؤسسة الإمام زيد بن علي الثقافية. 
r. . موقف أئمة الزيدية من المخالفين (عبدالله بن حمزة نموذجاً)

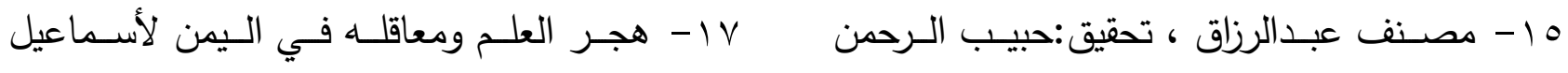
الأعظمـي، الناشـر : المجلس العلمي- الهند المكتب الأكـوع ، دار الفكـر ، دمشـق - سـوريا ، الطبعـة

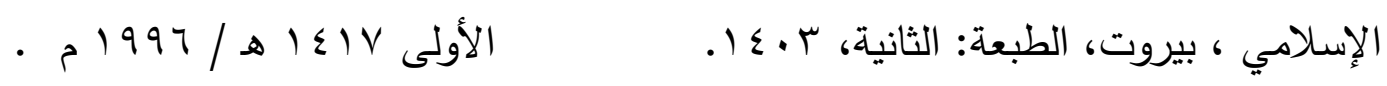
7 ا 1 - معجم البلدان و القبائل اليمنية،إبراهيم المقحفي

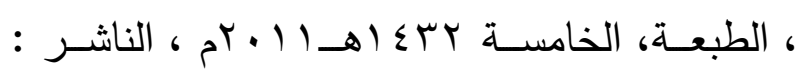

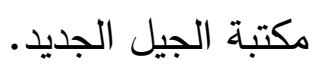




\title{
Attitude of Zadizm Imams towards Opponents Abdullah bin Hamza as A model
}

\author{
Dr. Abdulrahman Ali Ahmad Al Zahrani \\ Assistant Prof. of Aqedah (Faith) \\ Islamic Studies Department, \\ Faculty of Sciences and Arts, Al Mandaq \\ Albaha University
}

\begin{abstract}
Zaydi sect towards the sects that disagree with them through studying the most prominent imam of them: Abdullah bin Hamza. The research found that Zaydism accuses their opponents of blasphemy and call for killing, fighting them, permissibility of their funds, captivity of their women and offspring. Their extremism reached to stand against the companions, Allah blesses them. In addition, they rejected the imamate of the three sheikhs, Allah blesses them all, and they accuse of blasphemy all who do not restrict the imamate to Al Hassan and Al Hussein bin Ali. They also accuse of blasphemy who proved the Divine attributes, the creation of worshippers' deeds, the one who does not believe in their faith of imamate and they call for fighting and killing them.

The research indicated the Zaydism extremist attitude towards their opponents and applied the Ayahs of greatest blasphemy on Muslim, only for their negative attitude of imamate issue.
\end{abstract}

Keywords: Attitude, Zadizm, opponent, bin Hamza 